\title{
Exclusive Hydrogen Generation by Electrocatalysts Coated with an Amorphous Chromium-Based Layer Achieving Efficient Overall Water Splitting
}

\author{
Muhammad Qureshi, Tatsuya Shinagawa, ${ }^{\dagger}$ Nikolaos Tsiapis, and Kazuhiro Takanabe*(0) \\ King Abdullah University of Science and Technology (KAUST), KAUST Catalysis Center (KCC) and Physical Sciences and \\ Engineering Division, 4700 KAUST, Thuwal 23955-6900, Saudi Arabia
}

\section{Supporting Information}

ABSTRACT: Successful conversion of renewable energy to useful chemicals requires efficient devices that can electrocatalyze or photocatalyze redox reactions, e.g., overall water splitting. Excellent electrocatalysts for the hydrogen evolution reaction (HER), such as $\mathrm{Pt}$, can also cause other sidereactions, including the water-forming back-reaction from $\mathrm{H}_{2}$ and $\mathrm{O}_{2}$ products. A Cr-based amorphous layer coated on catalysts can work as a successful surface modifier that avoids the back-reaction, but its capabilities and limitations toward other species have not been studied. Herein, we investigated the Cr-based layer on Pt from perspectives of both electrocatalysis and photocatalysis using redox-active molecules/ions $\left(\mathrm{O}_{2}\right.$, ferricyanide, $\mathrm{IO}_{3}^{-}, \mathrm{S}_{2} \mathrm{O}_{8}{ }^{2-}, \mathrm{H}_{2} \mathrm{O}_{2}$, and $\mathrm{CO}$ gas). Our systematic study revealed that utilization of the $\mathrm{Cr}$-based layer realized an exclusive cathodic reaction only to HER, even in the presence of the aforementioned reactive

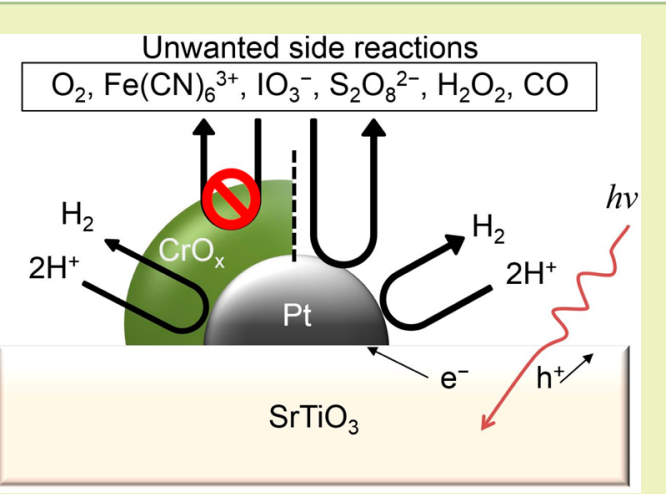
species, suggesting that $\mathrm{Cr}$-based layers work as membranes, as well as corrosion and poison inhibition layers. However, the Crbased layer experienced self-oxidation and dissolved into the aqueous phase when a strong oxidizing agent or low $\mathrm{pH}$ was present. Presented herein are fundamental and critical aspects of the Cr-based modifier, which is essential for the successful and practical development of solar fuel production systems.

KEYWORDS: Photocatalysis, Electrocatalysis, Membrane, Ferricyanide, Iodate, Persulfate, Peroxide, Carbon monoxide

\section{INTRODUCTION}

Changing from fossil fuels to solar fuels, e.g., generating $\mathrm{H}_{2}$ using sunlight, has been pursued for many decades. ${ }^{1}$ One option is to use photocatalyst powders that are capable of converting solar energy into usable chemical energy, e.g., photocatalytic water splitting. ${ }^{2}$ Successful photocatalytic water splitting requires a suitable band gap in a photon-absorbing semiconductor that is wider than the Gibbs free energy change of the water-splitting reaction $\left(\Delta G^{\circ}=237 \mathrm{~kJ} \mathrm{~mol}^{-1} \approx 1.23\right.$ $\mathrm{eV}) \cdot{ }^{1,3}$ In addition, its conduction/valence band position has to be more negative/positive than that of the surface reduction/ oxidation reactions, respectively, to drive surface redox reactions, specifically, the cathodic hydrogen evolution reaction (HER) and the anodic oxygen evolution reaction (OER) in the case of overall water splitting. Furthermore, in many cases, it is essential to decorate semiconductor surfaces with cocatalysts to facilitate charge separation ${ }^{4}$ and/or surface redox reactions (functioning as electrocatalysts). ${ }^{5,6}$ Noble metals, especially Pt, are typically used as cocatalysts that are known for their high activity toward HER because they possess the optimal binding energy for the reaction intermediates. ${ }^{7}$ However, most noble metal cocatalysts also actively reduce oxygen back into water, i.e., the oxygen reduction reaction (ORR), which leads to a decrease in the overall efficiency of water splitting. ${ }^{8}$ Due to these complexities and difficulties, the reported best solar-tohydrogen efficiency for photocatalytic overall water splitting so far is merely $1 \%,{ }^{9}$ which is still greatly inferior to the benchmarking efficiency of $10 \% .^{10}$

Core-shell structured cocatalysts have been reported to be successful in photocatalytic overall water splitting and selectively suppress the undesired back-reaction. The first successful core-shell material was reported by Maeda et al., ${ }^{11}$ who decorated rhodium nanoparticles with a chromium shell. ${ }^{12-17}$ Some other successful core-shell structures have been reported, for example, a $\mathrm{NiO}_{x}$ shelli; ${ }^{18-20} \mathrm{Ti}, \mathrm{Nb}$, and $\mathrm{Ta}$ oxyhydroxide shells; ${ }^{21}$ and a Mo shell. ${ }^{22}$ Although the coreshell structured materials have seen their success, there have been few studies reported on the functionalities of shell materials in detail. The surface electrochemical phenomena occurring on the surface during photocatalytic reactions can be separately studied by electrochemical methods. One such study was reported by Yoshida et al. ${ }^{23}$ and explicitly revealed that the $\mathrm{CrO}_{x}$ layer around noble metals indeed electrochemically enabled selective HER in the presence of oxygen. Such a

\footnotetext{
Received: May 29, 2017

Revised: July 13, 2017

Published: August 8, 2017
} 
mechanistic study on the photocatalysis from the viewpoint of electrochemistry helps us understand and rationalize the complicated photocatalysis phenomena. ${ }^{24,25}$

In this context, we examined the $\mathrm{CrO}_{x}$ layer on $\mathrm{Pt}$ in both electrocatalytic and photocatalytic hydrogen evolution systems in detail to reveal its capabilities, function, and limitations by using a variety of probe species $\left(\left[\mathrm{Fe}\left(\mathrm{CN}_{6}\right)\right]^{3-}, \mathrm{NaIO}_{3}\right.$, $\mathrm{Na}_{2} \mathrm{~S}_{2} \mathrm{O}_{8}, \mathrm{H}_{2} \mathrm{O}_{2}$, and $\mathrm{CO}$ ). $\mathrm{H}_{2} \mathrm{O}_{2}$ was considered in this study because it can be the product of water splitting via anodic reactions, which can be reduced on the cathodic side instead of HER taking place, leading to a decrease in efficiency. ${ }^{26}$ Probe species such as $\mathrm{Fe}^{2+} / \mathrm{Fe}^{3+}$ and $\mathrm{I}^{-} / \mathrm{IO}_{3}{ }^{-}$were tested as they are the most commonly used redox mediators in Z-scheme photocatalytic reactions. However, current Z-scheme systems suffer from low efficiencies because the selectivity is not wellcontrolled and the reduction/oxidation reactions of these redox mediators prevail over the desired hydrogen/oxidation evolution reactions, leading to an internal short circuit. ${ }^{27,28}$ Selectivity toward HER in the presence of $\mathrm{Fe}^{3+}$ and $\mathrm{IO}_{3}{ }^{-}$is of great significance to achieve efficient $\mathrm{Z}$-scheme type systems. Persulfate was tested because it is a common sacrificial reagent in photocatalytic systems to examine the anodic reaction of $\mathrm{OER}^{29}$ and also has a highly positive standard potential of 2.01 vs standard hydrogen electrode (SHE), meaning it functions as a strong oxidizing agent from the viewpoint of thermodynamics. The investigation of the $\mathrm{CrO}_{x}$ layer in the presence of a stronger oxidizing agent than $\mathrm{O}_{2}$ allows the study of the layer in harsher conditions. Finally, $\mathrm{CO}$ gas was tested as it is known to poison noble metal catalysts ${ }^{30}$ and would help determine the universality of the $\mathrm{CrO}_{x}$ layer. Our systematic study revealed that, in both electrocatalytic and photocatalytic systems, the $\mathrm{CrO}_{x}$ shell universally achieves selective cathodic hydrogen production in the presence of the aforementioned species. Nevertheless, a critical drawback was also identified: when oxidizing agents that can locally oxidize $\mathrm{Cr}^{3+}$ are present, the $\mathrm{CrO}_{x}$ shell undergoes oxidative dissolution, leading to apparent loss in its performance. The present work provides fundamental details on the $\mathrm{CrO}_{x}$ modifier in both electrocatalytic and photocatalytic systems that shed light on the further development of solar fuel production systems.

\section{METHODS}

Materials. The following chemicals were used: $\mathrm{Na}_{2} \mathrm{PtCl}_{6} \cdot 6 \mathrm{H}_{2} \mathrm{O}$ (>98\%, Sigma-Aldrich), $\mathrm{NaIO}_{3}$ (>99.5\%, Sigma-Aldrich), $\mathrm{Na}_{2} \mathrm{~S}_{2} \mathrm{O}_{8}$ (>99.0\%, Sigma-Aldrich), $\mathrm{SrCl}_{2}$ (>99.995\%, Sigma-Aldrich), $\mathrm{Na}_{2} \mathrm{SO}_{4}$ (>99.99\%, Sigma-Aldrich), $\mathrm{KH}_{2} \mathrm{PO}_{4}$ (>99.995\%, Sigma-Aldrich), $\mathrm{K}_{2} \mathrm{HPO}_{4}$ (>99.995\%, Sigma-Aldrich), $\mathrm{K}_{2} \mathrm{CrO}_{4}$ (>99.9\%, Fisher Scientific), $\mathrm{NaOH}$ (>99.9\%, Sigma-Aldrich), $\mathrm{K}_{3}\left[\mathrm{Fe}(\mathrm{CN})_{6}\right](>99.9$, Sigma-Aldrich), $\mathrm{K}_{3}\left[\mathrm{Fe}(\mathrm{CN})_{6}\right]$ (>99.9, Sigma-Aldrich), $\mathrm{SrTiO}_{3}$ (>99.9, Wako Pure Chemical Industries), and $\mathrm{H}_{2} \mathrm{O}_{2}\left(30 \%\right.$ with $\mathrm{H}_{2} \mathrm{O}$, SigmaAldrich). The water used in all experiments was obtained from a MilliQ Academic system from Millipore with a resistivity of $18.2 \mathrm{M} \Omega \mathrm{cm}$. The $\mathrm{pH}$ was determined using a $\mathrm{pH}$ electrode from Fisher Scientific. All reagents were provided by commercial suppliers and used without further modification.

Electrochemistry. A research-grade BioLogic VMP3 potentiostat was used for all electrochemical measurements. A conventional singlecompartment, three-electrode system was used for electrochemical protocols. Rotating disk electrodes (RDEs) of polycrystalline Pt (3.0 mm diameter, $0.071 \mathrm{~cm}^{2}$ geometric surface area) were used as working electrodes. Before each measurement, the disk electrode was polished first with $1 \mu \mathrm{m}$ of diamond and then with $0.05 \mu \mathrm{m}$ of alumina (both purchased from BAS, Inc.). The disk rotation speed was controlled to be 900-4900 rpm. $\mathrm{CrO}_{x}$ was deposited on the $\mathrm{Pt} \mathrm{RDE}$ by chronopotentiometry (CP) at $-20 \mu \mathrm{A}$ for $10 \mathrm{~min}$ in $0.5 \mathrm{M} \mathrm{K}_{2} \mathrm{CrO}_{4}$ solution at $\mathrm{pH}=9.7 .^{23}$ (See Figure $\mathrm{S} 1$ for details.) A Pt wire was used as the counter electrode in most experiments, unless otherwise stated. $\mathrm{Ag} / \mathrm{AgCl}$ (saturated $\mathrm{KCl}$ ) was used as the reference electrode for most experiments, and a $\mathrm{Hg} / \mathrm{HgO}$ electrode was used at alkaline $\mathrm{pH}(>13)$. Before and during the measurements, $\mathrm{Ar}$ (99.999\%), $\mathrm{H}_{2}$ (99.9999\%), or $\mathrm{O}_{2}(99.9995 \%)$ was continuously supplied through the electrolyte. Cyclic and linear sweep voltammograms were recorded at a scan rate of $50 \mathrm{mV} \mathrm{s}^{-1}$ at room temperature. All reported potentials have been $i R$ corrected (i.e., ohmic drop) and are referenced to either the reversible hydrogen electrode (RHE) or the standard hydrogen electrode (SHE), as specified in each figure.

Photocatalysis. As-purchased $\mathrm{SrTiO}_{3}$ and $\mathrm{SrCl}_{2}$ (mole ratio of 1:5) were ground with a mortar and pestle followed by a flux treatment at $1273 \mathrm{~K}$ for $10 \mathrm{~h}$ to make highly crystalline $\mathrm{SrTiO}_{3} \cdot{ }^{31}$ Once the powder cooled to room temperature, it was washed with water until no more chloride salt was detected by the $\mathrm{AgNO}_{3}$ test. Pt was deposited on the surface of $\mathrm{SrTiO}_{3}$ via wet impregnation for a calculated $0.5 \mathrm{wt}$ \% loading using $25 \mu \mathrm{L}$ of $\mathrm{Na}_{2} \mathrm{PtCl}_{6}$ (0.1 M solution), $5 \mathrm{~mL}$ of water, and $100 \mathrm{mg}(0.54 \mathrm{mmol})$ of $\mathrm{SrTiO}_{3}$ that were mixed over a water bath until all the water evaporated. The powder underwent heat treatment at $573 \mathrm{~K}$ for $1 \mathrm{~h}$. The $\mathrm{Pt} / \mathrm{SrTiO}_{3}$ was collected and used for the photocatalytic reaction. $\mathrm{CrO}_{x}$ was deposited on $\mathrm{Pt} / \mathrm{SrTiO}_{3}$ via photodeposition. Typically, $50 \mathrm{mg}$ of $\mathrm{Pt} / \mathrm{SrTiO}_{3}$ was dispersed by sonication in $100 \mathrm{~mL}$ of $2 \mathrm{mM} \mathrm{K} \mathrm{CrO}_{4}$ solution (see Figure S2 for details). The photocatalytic powder was placed in a photoreactor and irradiated for $6 \mathrm{~h}$. The photocatalytic reactions were conducted at 100 Torr Ar gas in a circulating batch reactor equipped with an online gas chromatograph (GC; Bruker 450 GC, TCD, Ar carrier gas, molecular sieve 13X) that was connected to a vacuum line. A Xe lamp (CERMAX PE300-BF, $300 \mathrm{~W}$ ) was used as the light source, and the irradiation wavelength was controlled with a combination of a cold mirror and a water filter $(300<\lambda<800 \mathrm{~nm})$.

\section{RESULTS AND DISCUSSION}

In this study, the functionality of $\mathrm{CrO}_{x}$ shells is studied in both electrocatalytic and photocatalytic systems in detail. For the electrochemical experiments, a polycrystalline Pt RDE with a geometric surface area of $0.071 \mathrm{~cm}^{2}$ was used as the working electrode. Figure 1a shows a cyclic voltammogram (CV) of the Pt RDE in $0.5 \mathrm{M} \mathrm{Na}_{2} \mathrm{SO}_{4}$ solution at $\mathrm{pH} 13$ as a representative case with $\mathrm{O}_{2}$ bubbling at $3600 \mathrm{rpm}$. In the figure, below $0.9 \mathrm{~V}$ on the RHE scale, an increasing cathodic current density was observed; this current density reached a constant value at $\sim 0.5$ $\mathrm{V}$ vs RHE. The constant current density of $-5 \mathrm{~mA} \mathrm{~cm}^{-2}$ at $\sim 0-0.5 \mathrm{~V}$ vs RHE indicates limitation by mass transport that is ascribable to oxygen diffusion-limited ORR (water-forming reaction). ${ }^{32}$ Further increases in the cathodic current below $0 \mathrm{~V}$ vs RHE are assigned to HER, as we have previously reported. ${ }^{33,34} \mathrm{CrO}_{x}$ was electrochemically deposited on the $\mathrm{Pt}$ $\mathrm{RDE}$ by chronopotentiometry following literature procedures $\left(-20 \mu \mathrm{A}\right.$ for $10 \mathrm{~min}$ in $0.5 \mathrm{M} \mathrm{K}_{2} \mathrm{CrO}_{4}$ solution; see Figure $\mathrm{S} 1$ for a discussion on the deposition conditions) and was tested under the same conditions as the bare $\mathrm{Pt} \mathrm{RDE}$. The $\mathrm{CrO}_{x} / \mathrm{Pt}$ RDE showed negligible current at $0-0.7 \mathrm{~V}$ vs RHE, and increasing cathodic current below $0 \mathrm{~V}$ vs RHE was ascribable to HER. The absence of limiting diffusion currents clearly suggests nearly complete selective suppression of ORR by the $\mathrm{CrO}_{x}$ layer. These observations demonstrated that the $\mathrm{CrO}_{x}$ layer selectively suppressed ORR without significantly losing HER activity of the substrate $(\mathrm{Pt})$, consistent with literature reports. $^{23}$

For the investigation of photocatalytic reactions, UVresponsive $\mathrm{SrTiO}_{3}$ was chosen as a model photocatalyst because its conduction band edge is more negative than the HER equilibrium potential and its valence band edge is more positive than the OER equilibrium potential, indicating that this 
(a)

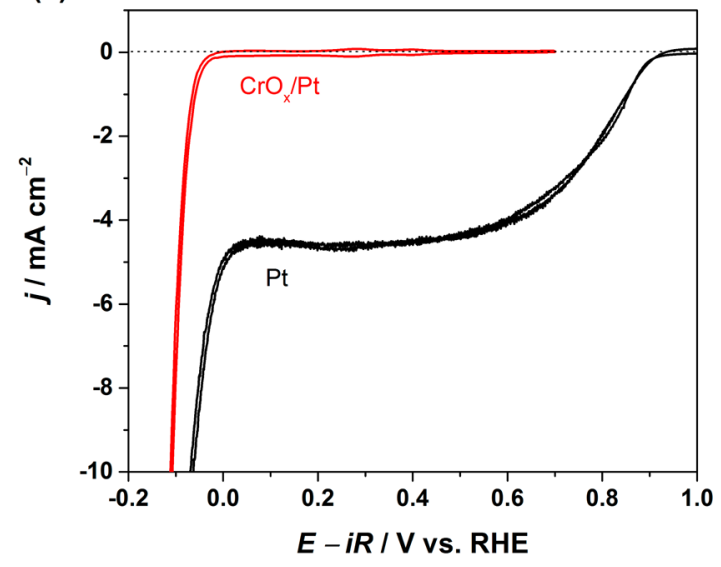

(b)

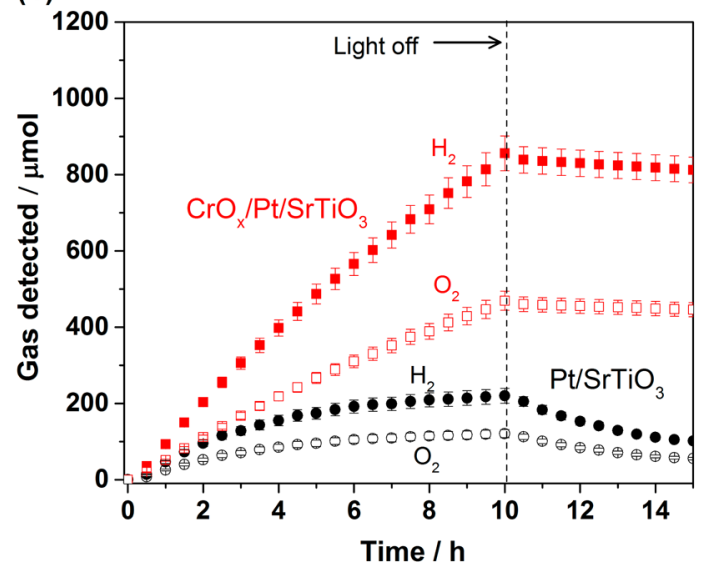

Figure 1. (a) Cyclic voltammograms over bare $\mathrm{Pt}$ and $\mathrm{Cr}$-modified $\mathrm{Pt}$ $\left(\mathrm{CrO}_{x} / \mathrm{Pt}\right)$ disk electrodes in $0.5 \mathrm{M} \mathrm{Na}$-sulfate at $\mathrm{pH} 13$ (conditions: $3600 \mathrm{rpm}, 50 \mathrm{mV} \mathrm{s}^{-1}, \mathrm{O}_{2}$ bubbling, and $298 \mathrm{~K}$ ). (b) Photocatalytic gas evolution time course for $\mathrm{Pt} / \mathrm{SrTiO}_{3}$ and $\mathrm{CrO}_{x} / \mathrm{Pt} / \mathrm{SrTiO}_{3}(100 \mathrm{~mL}$ of $0.1 \mathrm{M} \mathrm{NaOH}$ solution, under UV light irradiation $(300<\lambda<800 \mathrm{~nm})$, $50 \mathrm{mg}$ of catalyst, volume of reactor $=512 \mathrm{~mL}$ ).

semiconductor is thermodynamically capable of overall water splitting under UV light irradiation. ${ }^{3}$ To facilitate the surface redox reactions, the surface of $\mathrm{SrTiO}_{3}$ was decorated with an optimized loading of $0.4 \mathrm{wt} \%$ of $\mathrm{Pt}$ via the wet impregnation method. Figure 2a shows the transmission electron microscopy (TEM) image, and Figure 2b shows the corresponding energydispersive spectroscopy (EDS) analysis for $\mathrm{Pt} / \mathrm{SrTiO}_{3}$, revealing that the $\mathrm{Pt}$ nanoparticles on the surface ranged from 0.5 to $4 \mathrm{~nm}$ in size. The EDS analysis shows clear signals of $\mathrm{Sr}$ and $\mathrm{Ti}$ from $\mathrm{SrTiO}_{3}$ and $\mathrm{Pt}$ from the nanoparticles (and $\mathrm{Cu}$ from the TEM grid). $\mathrm{CrO}_{x}$ was photodeposited on the surface of $\mathrm{Pt} / \mathrm{SrTiO}_{3}$ from a $2 \mathrm{mM} \mathrm{K} \mathrm{CrO}_{4}$ solution. In the sample after deposition, EDS (Figure $2 \mathrm{~d}$; also see Figure S3) showed an additional peak at $5.4 \mathrm{keV}$ that is ascribable to $\mathrm{Cr}$, and X-ray photoelectron spectroscopy (XPS) spectra (Figure S4) exhibited peaks at approximately 576 and $586 \mathrm{eV}$ that correspond to a $\mathrm{Cr} 2 \mathrm{p}$ orbital $\left(\mathrm{Cr}^{3+}\right)$, indicating that $\mathrm{Cr}^{6+}$ in the solution was successfully reduced onto $\mathrm{Pt} / \mathrm{SrTiO}_{3} \cdot{ }^{35}$ Notably, X-ray diffraction (XRD) profiles (Figure S5a) did not exhibit any changes in the bulk structure before/after the deposition, and UV-vis spectra (Figure S5b) indicated negligible influence of $\mathrm{Pt}$ and $\mathrm{CrO}_{x}$ on the absorption edge. (a)

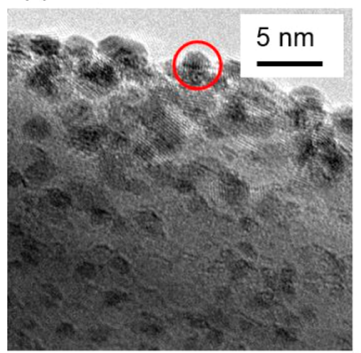

(b)

(c)

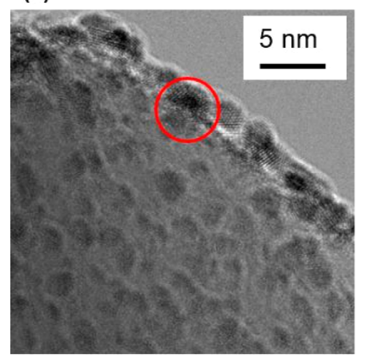

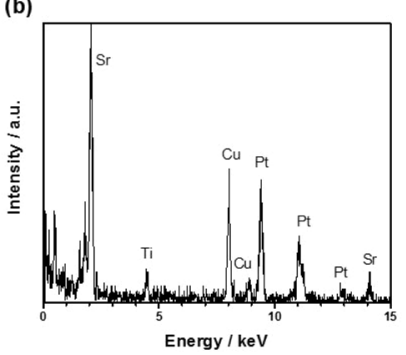

(d)

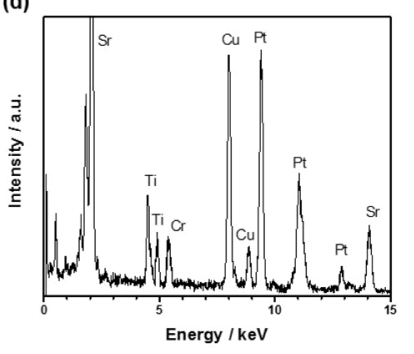

Figure 2. TEM of (a) $\mathrm{Pt} / \mathrm{SrTiO}_{3}$ and (c) $\mathrm{CrO}_{x} / \mathrm{Pt} / \mathrm{SrTiO}_{3}$, with corresponding EDS analysis (b) and (d), respectively. Red circles in TEM images indicate the spots where EDS analysis was performed.

The photocatalytic gas evolution time course for $\mathrm{Pt} / \mathrm{SrTiO}_{3}$ in $0.1 \mathrm{M} \mathrm{NaOH}$ solution with UV light irradiation is presented in Figure 1b. Initial gas evolution rates at $0.5 \mathrm{~h}$ were approximately $60\left(\mathrm{H}_{2}\right)$ and $30\left(\mathrm{O}_{2}\right) \mu \mathrm{mol} \mathrm{h}^{-1}$. The observed $\mathrm{H}_{2} / \mathrm{O}_{2}$ ratio of 2 was consistent with the stoichiometry of water splitting, showing that the prepared $\mathrm{Pt} / \mathrm{SrTiO}_{3}$ was capable of photocatalytically splitting water into $\mathrm{H}_{2}$ and $\mathrm{O}_{2}$. The gas evolution rates decreased over time to $\sim 0$ after $8 \mathrm{~h}$. In addition, when the light was turned off after $10 \mathrm{~h}$ of irradiation, negative rates (approximately -50 and $-25 \mu \mathrm{mol} \mathrm{h}^{-1}$ for $\mathrm{H}_{2}$ and $\mathrm{O}_{2}$, respectively) were observed, which indicates that the water formation reaction from $\mathrm{H}_{2}$ and $\mathrm{O}_{2}$ occurred. The observed back-reaction rates were almost comparable to the initial rate, which unambiguously accounts for the observed negligible gas evolution rate at $\sim 8-10 \mathrm{~h}$ in the figure: $\mathrm{Pt} / \mathrm{SrTiO}_{3}$ is not only capable of splitting water molecules but also even catalyzes the back-reaction of water formation in the dark, which results in no apparent gas evolution in the steady state. For a successful water-splitting reaction, therefore, a strategy to selectively suppress the back-reaction is essential.

The photocatalytic gas evolution rates for $\mathrm{CrO}_{x} / \mathrm{Pt} / \mathrm{SrTiO}_{3}$ are shown in Figure $1 \mathrm{~b}$. The initial gas evolution rates were 120 $\left(\mathrm{H}_{2}\right)$ and $60\left(\mathrm{O}_{2}\right) \mu \mathrm{mol} \mathrm{h}$. The rates then dropped to a steady rate of $90\left(\mathrm{H}_{2}\right)$ and $45\left(\mathrm{O}_{2}\right) \mu \mathrm{mol} \mathrm{h}^{-1}$ after $4 \mathrm{~h}$, presumably because of any surface contaminants that were used as a sacrificial reagent, which was also the case for $\mathrm{Pt} / \mathrm{SrTiO}_{3}$. Indeed, the powder exhibited the rate of $90 \mu \mathrm{mol} \mathrm{h}^{-1}$ when it was reused multiple times for a total of $20 \mathrm{~h}$ (Figure S6). The evolved $\mathrm{H}_{2} / \mathrm{O}_{2}$ ratio was continuously 2 for the full duration of the experiment, consistent with the stoichiometry of water splitting. When the light was turned off after $10 \mathrm{~h}$, the rate dropped to almost zero, indicating no apparent back-reaction, which contrasted with the observation for $\mathrm{Pt} / \mathrm{SrTiO}_{3}$. These observations clearly show that the $\mathrm{CrO}_{x} / \mathrm{Pt} / \mathrm{SrTiO}_{3}$ successfully achieved overall water splitting.

On the basis of the observations for $\mathrm{Pt} / \mathrm{SrTiO}_{3}$ and $\mathrm{CrO}_{x} /$ $\mathrm{Pt} / \mathrm{SrTiO}_{3}$, we attempted the following quantitative rationalization of the reaction rate. The overall water splitting, 


$$
2 \mathrm{H}_{2} \mathrm{O} \rightleftharpoons 2 \mathrm{H}_{2}+\mathrm{O}_{2}
$$

is composed of HER and OER, which are shown in eq 2 and 3, respectively.

$$
\begin{aligned}
& 2 \mathrm{H}_{2} \mathrm{O}+2 \mathrm{e}^{-} \rightleftharpoons \mathrm{H}_{2}+2 \mathrm{OH}^{-} \\
& 4 \mathrm{OH}^{-} \rightleftharpoons \mathrm{O}_{2}+2 \mathrm{H}_{2} \mathrm{O}+4 \mathrm{e}^{-}
\end{aligned}
$$

where $\mathrm{e}^{-}$denotes an electron. Importantly, the water-forming back-reaction is classified into (a) the electroless local reaction (thermal back-reaction of eq 1) and (b) the electrocatalytic reaction (back-reaction of eqs 2 and 3). Notably, the oxide surface is generally not capable of dissociating the $\mathrm{H}_{2}$ molecule, and thus the electrocatalytic hydrogen oxidation reaction (backreaction of eq 2) is barely problematic. ${ }^{36}$ The photocatalytic overall water-splitting reaction rate $r$ is thus described as follows:

$$
r=r_{\mathrm{f}}-r_{\mathrm{b}, \text { illum }}-r_{\mathrm{b}, \text { dark }}
$$

where $r_{\mathrm{f}}$ is the forward rate of photocatalytic water splitting, $r_{\mathrm{b}, \text { illum }}$ is the rate of the electrocatalytic back-reaction (ORR, backward reaction of eq 3 ), and $r_{\mathrm{b} \text {,dark }}$ is the electroless backreaction associated with eq 1 . Because $\mathrm{CrO}_{x} / \mathrm{Pt} / \mathrm{SrTiO}_{3}$ did not show apparent back-reactions (Figure 1b), the steady-state reaction rate of $90 \mu \mathrm{mol} \mathrm{h}{ }^{-1}$ likely corresponds to the true forward reaction rate $\left(r_{\mathrm{f}}\right)$. It should be noted that the initial rate of $\mathrm{Pt} / \mathrm{SrTiO}_{3}$ in Figure $1 \mathrm{~b}$ is close to $90 \mu \mathrm{mol} \mathrm{h}{ }^{-1}$, which is almost the same as the steady-state rate of $\mathrm{CrO}_{x} / \mathrm{Pt} / \mathrm{SrTiO}_{3}$. For $\mathrm{Pt} / \mathrm{SrTiO}_{3}$, when the light was turned off, a clear backreaction was observed with the rate of $40 \mu \mathrm{mol} \mathrm{h}^{-1}$, which can be regarded as the electroless back-reaction $\left(r_{\mathrm{b}, \mathrm{dark}}\right)$ in the presence of $200 \mu \mathrm{mol}$ of $\mathrm{H}_{2}$ and $100 \mu \mathrm{mol}$ of $\mathrm{O}_{2}$ in our recirculating batch reactor with a system volume of $512 \mathrm{~mL}$. Using eq $4, r_{\mathrm{b}, \mathrm{illum}}$ is therefore calculated to be $50 \mu \mathrm{mol} \mathrm{h}^{-1}$. This simple calculation revealed that more than half of the back-reaction for $\mathrm{Pt} / \mathrm{SrTiO}_{3}$ in our system could be accounted for by the electrocatalytic back-reaction. In addition, such an electrocatalytic back-reaction (ORR) can be separately investigated electrochemically. In the following sections, the photocatalytic and electrocatalytic reactions of the $\mathrm{CrO}_{x}$ layer are studied in various conditions to elucidate its limitations and capabilities.

Fe Redox. The redox reaction with ferro-/ferricyanide species was tested because it is an outer-sphere reaction, which is fundamentally different from the other reactions discussed, i.e., HER or ORR. Figure 3a shows CVs using pristine $\mathrm{Pt}$ and $\mathrm{CrO}_{x} / \mathrm{Pt} \mathrm{RDEs}$ in $10 \mathrm{mM} \mathrm{K}{ }_{3} \mathrm{Fe}(\mathrm{CN})_{6}$ with $1.5 \mathrm{~mol} \mathrm{~L}^{-1}$ of $\mathrm{K}$ phosphate solution with Ar bubbling $\left(\mathrm{KH}_{2} \mathrm{PO}_{4} / \mathrm{K}_{2} \mathrm{HPO}_{4}=80 /\right.$ 20, $\mathrm{pH} 5.8$; see Figure $\mathrm{S} 7$ for CVs in the absence of $\mathrm{K}_{3} \mathrm{Fe}(\mathrm{CN})_{6}$ under buffered conditions). Buffered solution was used to prevent $\mathrm{pH}$ changes in the system, and the near-neutral $\mathrm{pH}$ was chosen to avoid oxidation of $\mathrm{CrO}_{x}$ by $\mathrm{Fe}^{2+}$ (see Pourbaix diagram in Figure 9; see also the final section for discussion on the oxidative loss of $\mathrm{CrO}_{x}$ ). The Pt disk showed a constant current density of $-6 \mathrm{~mA} \mathrm{~cm} \mathrm{c}^{-2}$ at $0-0.7 \mathrm{~V}$ vs RHE, indicative of the diffusion-limited reduction of $\mathrm{Fe}^{3+}$ to $\mathrm{Fe}^{2+}$. The increase in the cathodic current when the potential was below $0 \mathrm{~V}$ vs RHE originated from HER. In contrast, when the surface of $\mathrm{Pt}$ was decorated with $\mathrm{CrO}_{x}$, no constant current was observed when the potential was above $0 \mathrm{~V}$ vs $\mathrm{RHE}$, indicating that $\mathrm{CrO}_{x} / \mathrm{Pt}$ was not capable of reducing $\mathrm{Fe}^{3+}$ in the solution. Nevertheless, an increase in the cathodic current was observed below $0 \mathrm{~V}$ vs RHE and was ascribable to HER, demonstrating that $\mathrm{CrO}_{x}$ can electrochemically realize selective HER without (a)

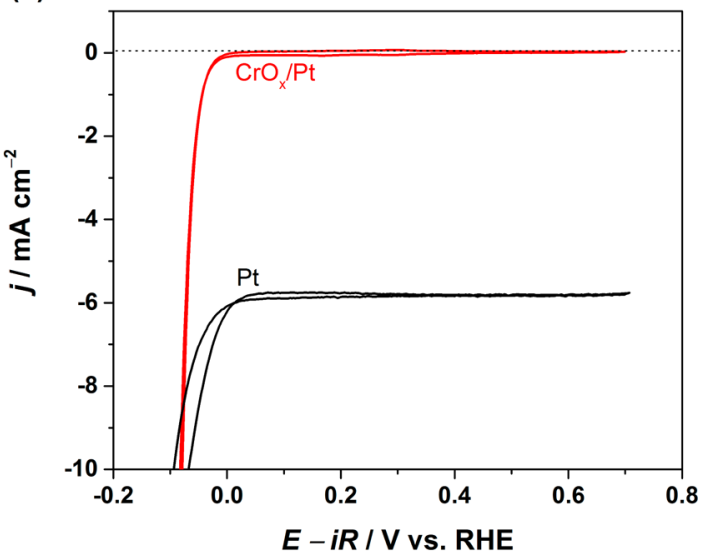

(b)

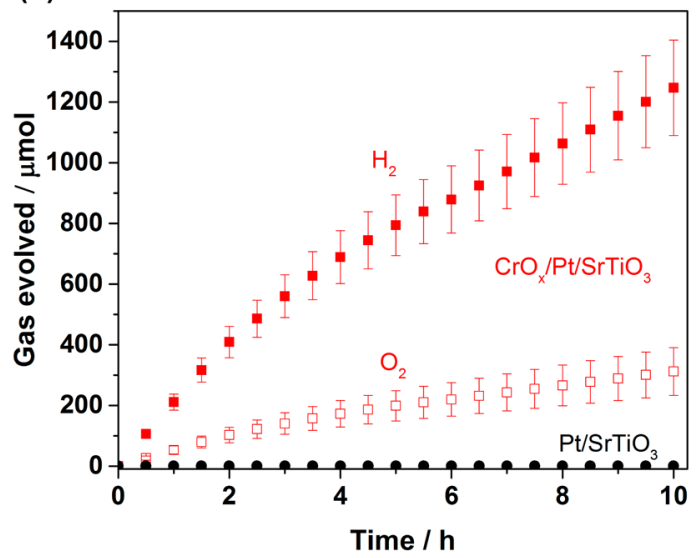

Figure 3. (a) Cyclic voltammograms over pristine $\mathrm{Pt}$ and $\mathrm{Cr}$-modified $\mathrm{Pt}\left(\mathrm{CrO}_{x} / \mathrm{Pt}\right)$ disk electrodes, recorded at a scan rate of $50 \mathrm{mV} \mathrm{s}^{-1}$, at a disk rotation speed of $3600 \mathrm{rpm}$ and at $298 \mathrm{~K}$ in $10 \mathrm{mM} \mathrm{K}_{3} \mathrm{Fe}(\mathrm{CN})_{6}+$ 1.5 M K-phosphate $\left(\mathrm{KH}_{2} \mathrm{PO}_{4} / \mathrm{K}_{2} \mathrm{HPO}_{4}=80 / 20, \mathrm{pH} 5.8\right)$, with $\mathrm{Ar}$ bubbling. (b) Photocatalytic activity time courses of $\mathrm{Pt} / \mathrm{SrTiO}_{3}$ and $\mathrm{CrO}_{x} / \mathrm{Pt} / \mathrm{SrTiO}_{3}$ in $1 \mathrm{mM} \mathrm{K}_{3} \mathrm{Fe}(\mathrm{CN})_{6}+1 \mathrm{mM} \mathrm{K}_{4} \mathrm{Fe}(\mathrm{CN})_{6}+0.5 \mathrm{M}$ $\mathrm{K}$-phosphate $\left(\mathrm{KH}_{2} \mathrm{PO}_{4} / \mathrm{K}_{2} \mathrm{HPO}_{4}=60 / 40\right)$ (under UV light irradiation $(300<\lambda<800 \mathrm{~nm}), 50 \mathrm{mg}$ of catalyst).

parasitic reduction of $\mathrm{Fe}^{3+}$. These results clearly indicate that the outer-sphere-type reaction of $\mathrm{Fe}^{3+}$ reduction cannot occur even on the surface of the $\mathrm{CrO}_{x}$ shell. According to theoretical predictions, the tunneling of electrons can occur at distances less than $\sim 1.5 \mathrm{~nm},{ }^{37}$ which is shorter than the thickness of the prepared $\mathrm{Cr}$ shell $(2 \mathrm{~nm})$. For $\mathrm{Fe}^{3+}$ to be reduced, the $\mathrm{Fe}^{3+}$ species thus must penetrate the $\mathrm{CrO}_{x}$ layer, which was most likely not allowed due to its membrane-like function. These rationales suggest that the $\mathrm{CrO}_{x}$ shell functions as a selective membrane through which hydronium ions, but not $\mathrm{Fe}^{3+}$, can penetrate, leading to selective hydrogen production.

Figure $3 \mathrm{~b}$ shows photocatalytic time courses of $\mathrm{Pt} / \mathrm{SrTiO}_{3}$ and $\mathrm{CrO}_{x} / \mathrm{Pt} / \mathrm{SrTiO}_{3}$ in $1.0 \mathrm{mM} \mathrm{K} \mathrm{K}_{3} \mathrm{Fe}(\mathrm{CN})_{6}+1.0 \mathrm{mM}$ $\mathrm{K}_{4} \mathrm{Fe}(\mathrm{CN})_{6}$ in $0.5 \mathrm{~mol} \mathrm{~L}{ }^{-1} \mathrm{~K}$-phosphate $\left(\mathrm{KH}_{2} \mathrm{PO}_{4} / \mathrm{K}_{2} \mathrm{HPO}_{4}=\right.$ $60 / 40 \mathrm{pH} 6)$ under UV light irradiation. A $0.5 \mathrm{~mol} \mathrm{~L}^{-1}$ solution was used instead of the $1.5 \mathrm{~mol} \mathrm{~L}^{-1}$ solution from the electrochemical study because the photocatalytic powder could not be dispersed in the denser buffer solution due to the buffer's high viscosity (see Figure S8 for rates with only buffer solution). A more detailed study of the effects of buffers in the photocatalytic system will be investigated in another paper. The photocatalytic experiments were performed at a concentration 
of the $\mathrm{Fe}$ couple that was 10 -fold lower than that in the electrochemical study, as the presence of $10 \mathrm{mM}$ Fe couple led to no gas evolution due to parasitic photon absorption by the Fe complex in the UV range (for UV-vis spectra of the iron species, see Figure S9). For $\mathrm{Pt} / \mathrm{SrTiO}_{3}$, no gas evolution was detected, presumably because the generated holes and electrons from the photocatalyst were used to cycle the redox couple between $\mathrm{Fe}^{2+}$ and $\mathrm{Fe}^{3+}$ (short circuit), which is thermodynamically more favored than water splitting. In the $\mathrm{CrO}_{x} / \mathrm{Pt} / \mathrm{SrTiO}_{3}$ system, the rate of $\mathrm{H}_{2}$ evolution started at $200 \mu \mathrm{mol} \mathrm{h}^{-1}$, while the $\mathrm{O}_{2}$ evolution rate started at $50 \mu \mathrm{mol} \mathrm{h}{ }^{-1}$. The gas evolution using a $\mathrm{CrO}_{x}$ shell was well-aligned with the electrochemical observation that was discussed in Figure 3a. However, the $\mathrm{H}_{2}$ / $\mathrm{O}_{2}$ ratio here was not $2: 1$, indicating that overall water splitting was not the case. The increase in $\mathrm{H}_{2}$ production is probably due to the $\mathrm{Fe}^{2+}$ ions acting as a sacrificial reagent by consuming a hole generated from the $\mathrm{SrTiO}_{3}$. A sharp decrease in the $\mathrm{H}_{2}$ evolution rate was observed between 2 and $6 \mathrm{~h}$, when it stabilized at $100 \mu \mathrm{mol} \mathrm{h} \mathrm{h}^{-1}$, and the oxygen evolution rate decreased to $25 \mu \mathrm{mol} \mathrm{h}{ }^{-1}$, which was lower than the hydrogen evolution rate in the absence of the Fe redox couple $(140 \mu \mathrm{mol}$ $\mathrm{h}^{-1}$; see Figure S8). Because $\sim 550 \mu \mathrm{mol}$ of $\mathrm{Fe}^{2+}$ was calculated to be remaining in solution after the whole reaction, the decrease in the rate could not be ascribed to the full consumption of the Fe complex. The lower activity is most likely due to competitive light absorption, as both iron species absorb especially close to $390 \mathrm{~nm}$ in the UV range, which is where the absorption edge of $\mathrm{SrTiO}_{3}$ is located. In addition, photocatalytic reactions were examined in the presence of only $\mathrm{K}_{3} \mathrm{Fe}(\mathrm{CN})_{6}$, which exhibited stoichiometric water splitting $\left(\mathrm{H}_{2} / \mathrm{O}_{2}\right.$ ratio of 2 ; data not shown $)$, which is consistent with our analysis.

The electrochemical study clearly revealed that the $\mathrm{CrO}_{x}$ shell achieved selective HER in the presence of $\mathrm{Fe}^{3+}$ ions, which was indeed the case for the photocatalytic system. The observed decrease in the performance during photocatalysis was thus rationalized as being most likely due to photon absorption rather than electrochemical phenomena. Therefore, in both electrocatalytic and photocatalytic systems, $\mathrm{CrO}_{x}$ shells were found to stably function to regulate the selectivity of the surface redox reactions, even for outer-sphere-type reactions.

$\mathrm{NaIO}_{3}$. The reduction of iodate, which is known as an electron acceptor and a redox mediator in Z-scheme systems, was investigated. Figure $4 \mathrm{a}$ presents $\mathrm{CVs}$ of $\mathrm{Pt}$ and $\mathrm{CrO}_{x} / \mathrm{Pt}$ RDEs in $0.1 \mathrm{M} \mathrm{NaOH}$ with $1 \mathrm{mM} \mathrm{NaIO}_{3}$ and $\mathrm{Ar}$ bubbling. When the pristine Pt RDE was used, a cathodic current arose at $\sim 0.6 \mathrm{~V}$ vs RHE and then plateaued when the potential reached $\sim 0.3 \mathrm{~V}$ vs RHE, which was ascribable to diffusion-limited reduction of $\mathrm{IO}_{3}{ }^{-}$. Below $\sim 0 \mathrm{~V}$ vs RHE, the cathodic current further increased, which was attributed to HER. In contrast, $\mathrm{CrO}_{x} / \mathrm{Pt}$ exhibited a substantial cathodic current only below 0 $\mathrm{V}$ vs RHE. The lack of any clear fingerprint of $\mathrm{IO}_{3}{ }^{-}$reduction when $\mathrm{CrO}_{x}$ was present clearly indicated that $\mathrm{CrO}_{x}$ enables the selective HER even in the presence of iodate; this behavior likely occurs because $\mathrm{CrO}_{x}$ prohibits the access of iodate to the reduction active sites.

Figure $4 \mathrm{~b}$ shows the photocatalytic time course for $\mathrm{Pt} /$ $\mathrm{SrTiO}_{3}$ and $\mathrm{CrO}_{x} / \mathrm{Pt} / \mathrm{SrTiO}_{3}$ in $0.1 \mathrm{M} \mathrm{NaOH}$ and $10 \mathrm{mM}$ $\mathrm{NaIO}_{3}$. For bare $\mathrm{Pt} / \mathrm{SrTiO}_{3}$, the $\mathrm{H}_{2}$ evolution rate was close to $0 \mu \mathrm{mol} \mathrm{h}{ }^{-1}$, indicating that $\mathrm{IO}_{3}{ }^{-}$was preferentially reduced, as observed in the electrochemical study. Interestingly, however, the corresponding $\mathrm{O}_{2}$ evolution rate was $25 \mu \mathrm{mol} \mathrm{h}{ }^{-1}$, which was lower than that of $\mathrm{CrO}_{x} / \mathrm{Pt} / \mathrm{SrTiO}_{3}$ in the absence of any
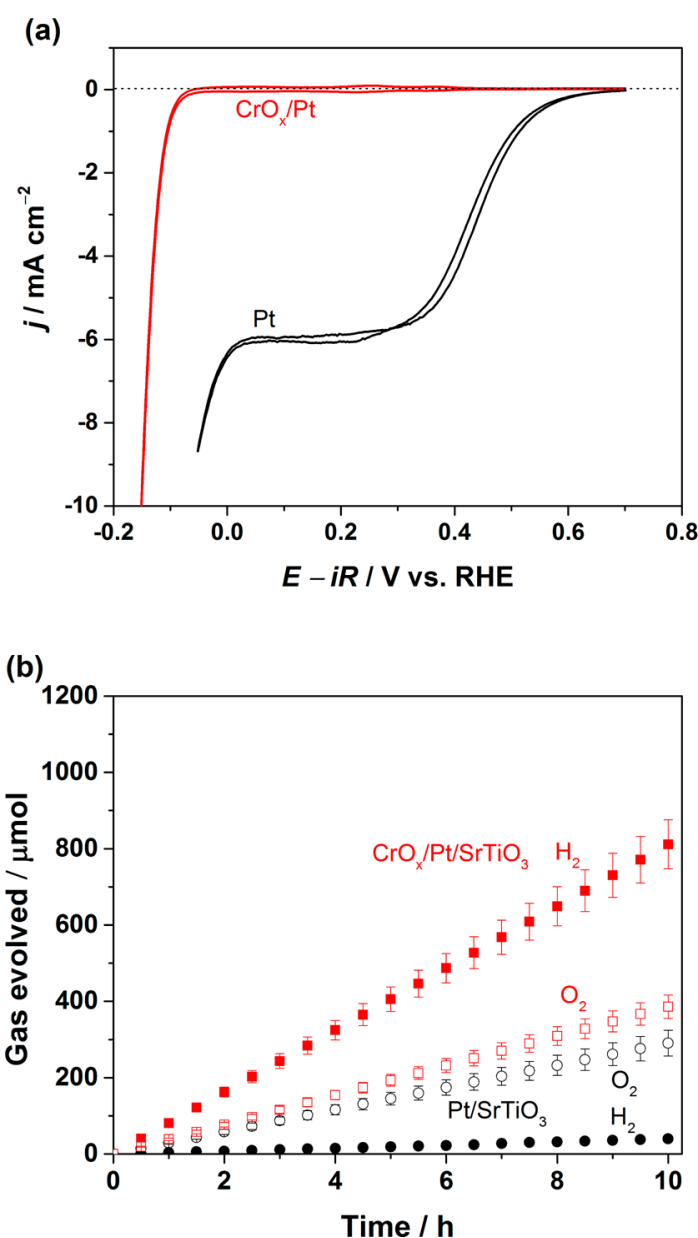

Figure 4. (a) Cyclic voltammograms over pristine Pt and Cr-modified $\mathrm{Pt}\left(\mathrm{CrO}_{x} / \mathrm{Pt}\right)$ disk electrodes recorded at a scan rate of $50 \mathrm{mV} \mathrm{s}^{-1}$, at disk rotation speed of $3600 \mathrm{rpm}$, and at $298 \mathrm{~K}$ in $0.1 \mathrm{M} \mathrm{NaOH}$ with 1 $\mathrm{mM} \mathrm{NaIO}$ and Ar bubbling. (b) Photocatalytic activity time courses of $\mathrm{Pt} / \mathrm{SrTiO}_{3}$ and $\mathrm{CrO}_{x} / \mathrm{Pt} / \mathrm{SrTiO}_{3}$ in $10 \mathrm{mM} \mathrm{NaIO}$ ( $100 \mathrm{~mL}$ of 0.1 $\mathrm{M} \mathrm{NaOH}$ solution, under UV light irradiation $(300<\lambda<800 \mathrm{~nm}), 50$ $\mathrm{mg}$ of catalyst).

sacrificial reagent (Figure 1). This apparent contradiction could be rationalized by the competitive oxidation of $\mathrm{I}^{-}$produced by the $\mathrm{IO}_{3}{ }^{-}$reduction, consistent with the previous reports on $\mathrm{Z}$ scheme systems. ${ }^{38,39} \mathrm{CrO}_{x} / \mathrm{Pt} / \mathrm{SrTiO}_{3}$, on the other hand, maintained steady performance throughout the duration of the experiment at a 2:1 ratio of $\mathrm{H}_{2}$ to $\mathrm{O}_{2}$ at a rate of 80 and 40 $\mu \mathrm{mol} \mathrm{h}{ }^{-1}$, respectively, indicating overall water splitting without unwanted side-reactions, consistent with the observation in the electrochemical study.

In summary, in both electrocatalysis and photocatalysis systems, the $\mathrm{CrO}_{x}$ shell was found to successfully suppress the reduction of iodate, leading to selective hydrogen production. In addition, our photocatalysis study demonstrated that the $\mathrm{SrTiO}_{3}$ surface is capable of oxidizing $\mathrm{I}^{-}$, which led to lower water splitting efficiency. Therefore, when the practical application of $\mathrm{CrO}_{x}$ shell was considered for redox-mediated photocatalytic reactions, additional strategies are required to regulate the side-reaction on the anodic side.

$\mathrm{Na}_{2} \mathrm{~S}_{2} \mathrm{O}_{8}$. Persulfate is one of the most commonly used sacrificial reagents (electron scavenger) in photocatalysis; however, electrochemical study of the reduction of persulfate in relevant conditions has rarely been reported. In this section, we extend our study to the reduction of persulfate in both 
electrocatalytic and photocatalytic systems. Figure 5a shows CVs of $\mathrm{Pt}$ and $\mathrm{CrO}_{x} / \mathrm{Pt}$ RDEs in $0.1 \mathrm{M} \mathrm{NaOH}$ with $1 \mathrm{mM}$

(a)

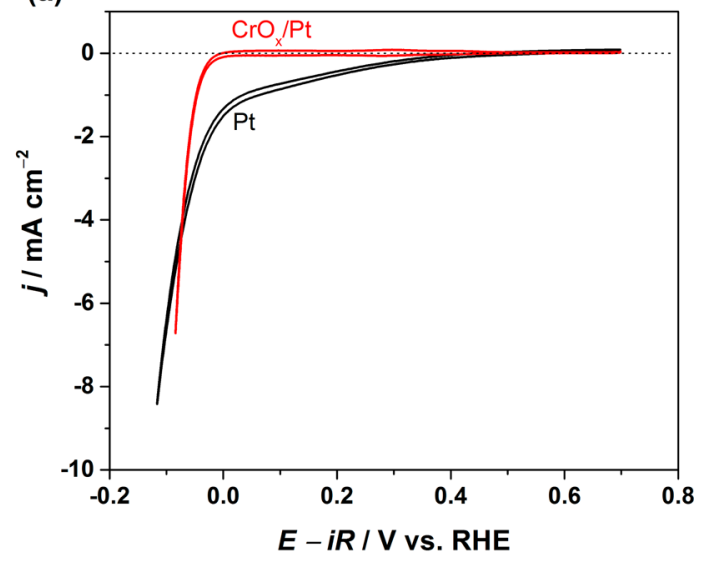

(b)

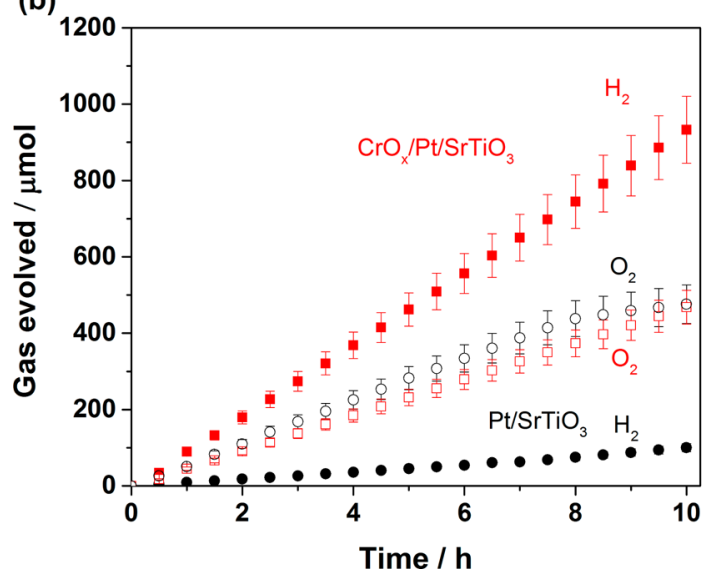

Figure 5. (a) Cyclic voltammograms over pristine $\mathrm{Pt}$ and $\mathrm{Cr}$-modified $\mathrm{Pt}\left(\mathrm{CrO}_{x} / \mathrm{Pt}\right)$ disk electrodes recorded at a scan rate of $50 \mathrm{mV} \mathrm{s}^{-1}$, at disk rotation speed of $3600 \mathrm{rpm}$, and at $298 \mathrm{~K}$ in $0.1 \mathrm{M} \mathrm{NaOH}$ with 1 $\mathrm{mM} \mathrm{Na}_{2} \mathrm{~S}_{2} \mathrm{O}_{8}$ and Ar bubbling. (b) Photocatalytic activity time courses of $\mathrm{Pt} / \mathrm{SrTiO}_{3}$ and $\mathrm{CrO}_{x} / \mathrm{Pt} / \mathrm{SrTiO}_{3}$ in $10 \mathrm{mM} \mathrm{Na} \mathrm{S}_{2} \mathrm{O}_{8}(100 \mathrm{~mL}$ of $0.1 \mathrm{M} \mathrm{NaOH}$ solution, under UV light irradiation $(300<\lambda<800 \mathrm{~nm})$, $50 \mathrm{mg}$ of catalyst).

$\mathrm{Na}_{2} \mathrm{~S}_{2} \mathrm{O}_{8}$ and Ar bubbling. The Pt RDE exhibited an increasing negative current density at applied potentials starting at $0.4 \mathrm{~V}$ vs RHE. At potentials less than $\sim 0 \mathrm{~V}$ vs RHE, the cathodic current became more apparent, which could be ascribable to HER. Surprisingly, this result showed that the reduction of persulfate in the electrochemical system is not particularly kinetically facile, even using $\mathrm{Pt}$, although persulfate is one of the most commonly used electron scavengers in photocatalytic systems. It could be speculated at this stage that its successful function as a sacrificial reagent originates from something more than surface electrochemical phenomena. Further study, which falls outside of our scope, seems essential in elucidating the phenomenon. On the other hand, $\mathrm{CrO}_{x} / \mathrm{Pt}$ showed no apparent cathodic current throughout the potential range from 0 to $0.7 \mathrm{~V}$ vs RHE, while a cathodic current ascribable to HER was observed below $0 \mathrm{~V}$ vs RHE. These results indicate that $\mathrm{CrO}_{x} / \mathrm{Pt}$ does not reduce $\mathrm{S}_{2} \mathrm{O}_{8}{ }^{2-}$ anions, instead maintaining the electrocatalytic activity of the substrate $(\mathrm{Pt})$ toward HER. Nevertheless, it should be noted that $\mathrm{CrO}_{x} / \mathrm{Pt}$ exhibited a decreasing cathodic current with successive cycles (see Figure S10), implying that the $\mathrm{CrO}_{x}$ shell could not stably function in the presence of persulfate, likely due to the local redox reaction $\left(\mathrm{S}_{2} \mathrm{O}_{8}{ }^{2-}\right.$ reduction and $\mathrm{Cr}^{3+}$ oxidation) while potential cycling. Detailed discussion of the local redox reactions is to be provided in the final section.

Figure $5 \mathrm{~b}$ shows the photocatalytic time course for $\mathrm{Pt} /$ $\mathrm{SrTiO}_{3}$ and $\mathrm{CrO}_{x} / \mathrm{Pt} / \mathrm{SrTiO}_{3}$ in $0.1 \mathrm{M} \mathrm{NaOH}$ and $10 \mathrm{mM}$ $\mathrm{Na}_{2} \mathrm{~S}_{2} \mathrm{O}_{8}$. $\mathrm{Pt} / \mathrm{SrTiO}_{3}$ showed minimal $\mathrm{H}_{2}$ evolution (a rate of $<5 \mu \mathrm{mol} \mathrm{h}{ }^{-1}$ ), while its $\mathrm{O}_{2}$ evolution rate was steady at $\sim 50$ $\mu \mathrm{mol} \mathrm{h}^{-1}$. Because the persulfate, which is known to function as a sacrificial reagent, was present, the corresponding reduction reaction here is the reduction of persulfate. The photocatalytic OER rate decreased to almost zero after $7 \mathrm{~h}$, which is most likely due to the consumption of the persulfate that was present in the solution. There was $1.0 \mathrm{mmol}$ of sacrificial reagent present in the solution, as it was $100 \mathrm{~mL}$ of a $10 \mathrm{mM} \mathrm{Na}_{2} \mathrm{~S}_{2} \mathrm{O}_{8}$ solution in the reactor. Decomposing each persulfate anion requires 2 electrons; therefore, $1.0 \mathrm{mmol}$ of $\mathrm{S}_{2} \mathrm{O}_{8}{ }^{2-}$ would correspond to $0.5 \mathrm{mmol}$ of $\mathrm{O}_{2}$. From Figure $5 \mathrm{~b}$, the amount of $\mathrm{O}_{2}$ that evolved was close to $450 \mu \mathrm{mol}$ in the first $8 \mathrm{~h}$ (before the rate decreased). When the $\mathrm{O}_{2}$ rate decreased, an increase in the $\mathrm{H}_{2}$ evolution rate was observed, corresponding to switching from reducing the sacrificial reagent to overall water splitting. A slight increase in the $\mathrm{H}_{2}$ evolution rate was observed, which coincided with the decrease of the $\mathrm{O}_{2}$ evolution rate and likely corresponded to a switch from the sacrificial reagent-assisted oxygen production to overall water splitting. When the surface of $\mathrm{Pt}$ was covered with a $\mathrm{CrO}_{x}$ shell, gas evolution rates of approximately $100\left(\mathrm{H}_{2}\right)$ and $50\left(\mathrm{O}_{2}\right) \mu \mathrm{mol} \mathrm{h}{ }^{-1}$ were observed throughout the duration of the experiment, as shown in Figure $5 \mathrm{~b}$. The ratio of hydrogen/oxygen evolution rates was 2 , clearly revealing that $\mathrm{CrO}_{x} / \mathrm{Pt} / \mathrm{SrTiO}_{3}$ was capable of evolving $\mathrm{H}_{2}$ and $\mathrm{O}_{2}$, even in the presence of persulfate. Interestingly, this material's photocatalytic water-splitting reaction rates were stable during the measurements $(10 \mathrm{~h})$, which contrasts with the observed decrease in its performance in the electrochemical study. The discrepancy can be rationalized by the fact that, during photocatalysis, $\mathrm{CrO}_{x} / \mathrm{Pt} / \mathrm{SrTiO}_{3}$ was continuously irradiated, i.e., the active site that is responsible for the hydrogen production had been likely kept under reducing conditions that can mitigate the local redox reaction between $\mathrm{Cr}^{3+}$ and $\mathrm{S}_{2} \mathrm{O}_{8}{ }^{2-}$ or avoid the oxidative loss of the $\mathrm{CrO}_{x}$ shell from the surface. This rationale implies that, for the $\mathrm{CrO}_{x}$ shell to stably function when oxidizing agents are present, substantial cathodic potential is required.

This section revealed that $\mathrm{CrO}_{x} / \mathrm{Pt}$ can selectively evolve hydrogen in both electrocatalytic and photocatalytic systems, even in the presence of a strong electron scavenger. Nonetheless, $\mathrm{CrO}_{x}$ was found to likely undergo local redox reactions with a strong oxidizing agent, probably due to the substantial thermodynamic driving force for the local redox reaction, which can be mitigated by keeping $\mathrm{CrO}_{x}$ in the reducing environment. Detailed discussion of the limitations of the $\mathrm{CrO}_{x}$ shell is in the final section.

$\mathrm{H}_{2} \mathrm{O}_{2}$. Depending on the nature of the oxidation active site, $\mathrm{H}_{2} \mathrm{O}_{2}$, instead of $\mathrm{O}_{2}$, can be generated during electrocatalysis and photocatalysis, which is known as an oxidizing agent. The cogeneration of such an oxidizing agent, i.e., $\mathrm{H}_{2} \mathrm{O}_{2}$, during water splitting can harm the catalyst. This section discusses the impact of the presence of $\mathrm{H}_{2} \mathrm{O}_{2}$ on the performance of $\mathrm{CrO}_{x}$ shells. Figure 6a shows the CVs of $\mathrm{Pt}$ and $\mathrm{CrO}_{x} / \mathrm{Pt} \mathrm{RDEs}$ in 0.1 $\mathrm{M} \mathrm{NaOH}$ with $1 \mathrm{mM} \mathrm{H}_{2} \mathrm{O}_{2}$ and Ar bubbling. The pristine $\mathrm{Pt}$ 
(a)

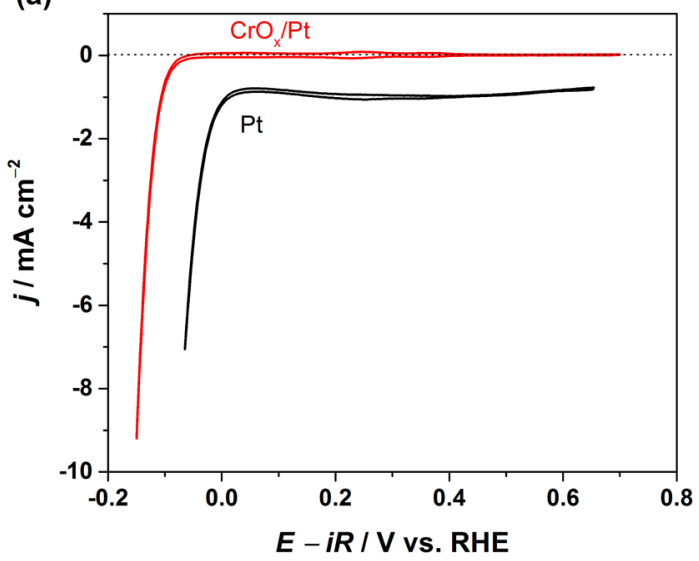

(b)

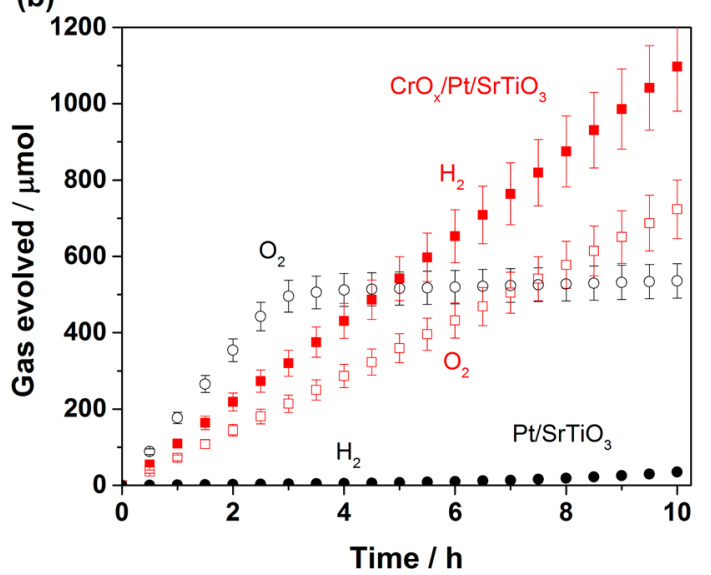

Figure 6. (a) Cyclic voltammograms over pristine $\mathrm{Pt}$ and $\mathrm{Cr}$-modified $\mathrm{Pt}\left(\mathrm{CrO}_{x} / \mathrm{Pt}\right)$ disk electrodes recorded at a scan rate of $50 \mathrm{mV} \mathrm{s}^{-1}$, at disk rotation speed of $3600 \mathrm{rpm}$, and at $298 \mathrm{~K}$ in $0.1 \mathrm{M} \mathrm{NaOH}$ with 1 $\mathrm{mM} \mathrm{H}_{2} \mathrm{O}_{2}$, and $\mathrm{Ar}$ bubbling (note: carbon paper was used as a counter electrode). (b) Photocatalytic activity time courses of $\mathrm{Pt} / \mathrm{SrTiO}_{3}$ and $\mathrm{CrO}_{x} / \mathrm{Pt} / \mathrm{SrTiO}_{3}$ in $10 \mathrm{mM} \mathrm{H} \mathrm{O}_{2}(100 \mathrm{~mL}$ of $0.1 \mathrm{M} \mathrm{NaOH}$ solution, under UV light irradiation $(300<\lambda<800 \mathrm{~nm}), 50 \mathrm{mg}$ of catalyst).

RDE exhibited a constant current when the potential was $<0.7$ $\mathrm{V}$ vs RHE, clearly showing that $\mathrm{H}_{2} \mathrm{O}_{2}$ was reduced and was limited by diffusion. Below $0 \mathrm{~V}$ vs RHE, a substantial increase in the reduction current was observed that can be assigned to HER. In contrast, $\mathrm{CrO}_{x} / \mathrm{Pt}$ showed negligible current density from 0 to $0.7 \mathrm{~V}$ vs RHE, and the apparent reduction current below $0 \mathrm{~V}$ vs $\mathrm{RHE}$ is ascribed to HER. The $\mathrm{CrO}_{x}$ shell stably functioned in the presence of $\mathrm{H}_{2} \mathrm{O}_{2}$ and can notably also prevent molecular species from penetrating through toward the Pt surface.

The photocatalytic time courses for $\mathrm{Pt} / \mathrm{SrTiO}_{3}$ and $\mathrm{CrO}_{x} /$ $\mathrm{Pt} / \mathrm{SrTiO}_{3}$ in $0.1 \mathrm{M} \mathrm{NaOH}$ and $10 \mathrm{mM} \mathrm{H}_{2} \mathrm{O}_{2}$ are shown in Figure $6 \mathrm{~b}$. Pt $/ \mathrm{SrTiO}_{3}$ showed an initial rate of $175 \mu \mathrm{mol} \mathrm{h}^{-1}$ for $\mathrm{O}_{2}$ evolution, which then rapidly decreased to $0 \mu \mathrm{mol} \mathrm{h}^{-1}$ after $4 \mathrm{~h}$, while the $\mathrm{H}_{2}$ evolution rate remained close to 0 for the full duration of the experiment. The decrease of $\mathrm{O}_{2}$ production to 0 corresponded to the full consumption of all $\mathrm{H}_{2} \mathrm{O}_{2}$ in solution. The same logic that was used in the $\mathrm{Na}_{2} \mathrm{~S}_{2} \mathrm{O}_{8}$ section applies: specifically, $0.5 \mathrm{mmol}$ of $\mathrm{O}_{2}$ is expected, as the decomposition of $\mathrm{H}_{2} \mathrm{O}_{2}$ is a $2 \mathrm{e}^{-}$process. After consuming $\mathrm{H}_{2} \mathrm{O}_{2}$, no $\mathrm{H}_{2}$ and $\mathrm{O}_{2}$ evolved, presumably because the ORR/OER pair prevailed because the system contained $500 \mu \mathrm{mol}$ of $\mathrm{O}_{2}$. It should be noted that $\mathrm{H}_{2} \mathrm{O}_{2}$ can be decomposed by UV light irradiation as well as the presence of catalysts such as $\mathrm{Pt}$, and thus, the rate observed here was not entirely ascribable to photocatalytic decomposition of $\mathrm{H}_{2} \mathrm{O}_{2} . \mathrm{CrO}_{x} / \mathrm{Pt} / \mathrm{SrTiO}_{3}$, on the other hand, evolved $\mathrm{H}_{2}$ at a rate of $110 \mu \mathrm{mol} \mathrm{h}$ and $\mathrm{O}_{2}$ at a rate of 75 $\mu \mathrm{mol} \mathrm{h}{ }^{-1}$. The ratio of hydrogen/oxygen production did not correspond to the stoichiometry of water splitting, most likely because of the decomposition of $\mathrm{H}_{2} \mathrm{O}_{2}$ under UV-light irradiation, as shown in Figure $\mathrm{S} 11$. Notably, the observed $\mathrm{H}_{2}$ production rate was almost comparable to that in the absence of $\mathrm{H}_{2} \mathrm{O}_{2}$, indicating that the $\mathrm{CrO}_{x}$ shell prevents the reduction of $\mathrm{H}_{2} \mathrm{O}_{2}$, consistent with the electrochemical study. Therefore, even if the oxidation site of the photocatalyst generates partial amounts of $\mathrm{H}_{2} \mathrm{O}_{2}$ instead of $\mathrm{O}_{2}$, the $\mathrm{CrO}_{x}$ shell can suppress the reduction of molecular $\mathrm{H}_{2} \mathrm{O}_{2}$, preventing harm to the catalyst.

CO. One of the most well-known molecules that can poison the catalyst is CO. Herein, we further extend our study to water splitting in the presence of $\mathrm{CO}$ to see if $\mathrm{CrO}_{x}$ shell can prevent poisoning of the $\mathrm{Pt}$ surface. Figure $7 \mathrm{a}$ shows $\mathrm{CVs}$ using the $\mathrm{Pt}$ and $\mathrm{CrO}_{x} / \mathrm{Pt} \mathrm{RDEs}$ in $0.1 \mathrm{M} \mathrm{NaOH}$ solution with $1 \% \mathrm{CO} / \mathrm{Ar}$ bubbling. The Pt RDE exhibited almost negligible currents at potentials from -0.1 to $0.7 \mathrm{~V}$ vs RHE, and a slight increase in the cathodic current, ascribable to HER, was observed at
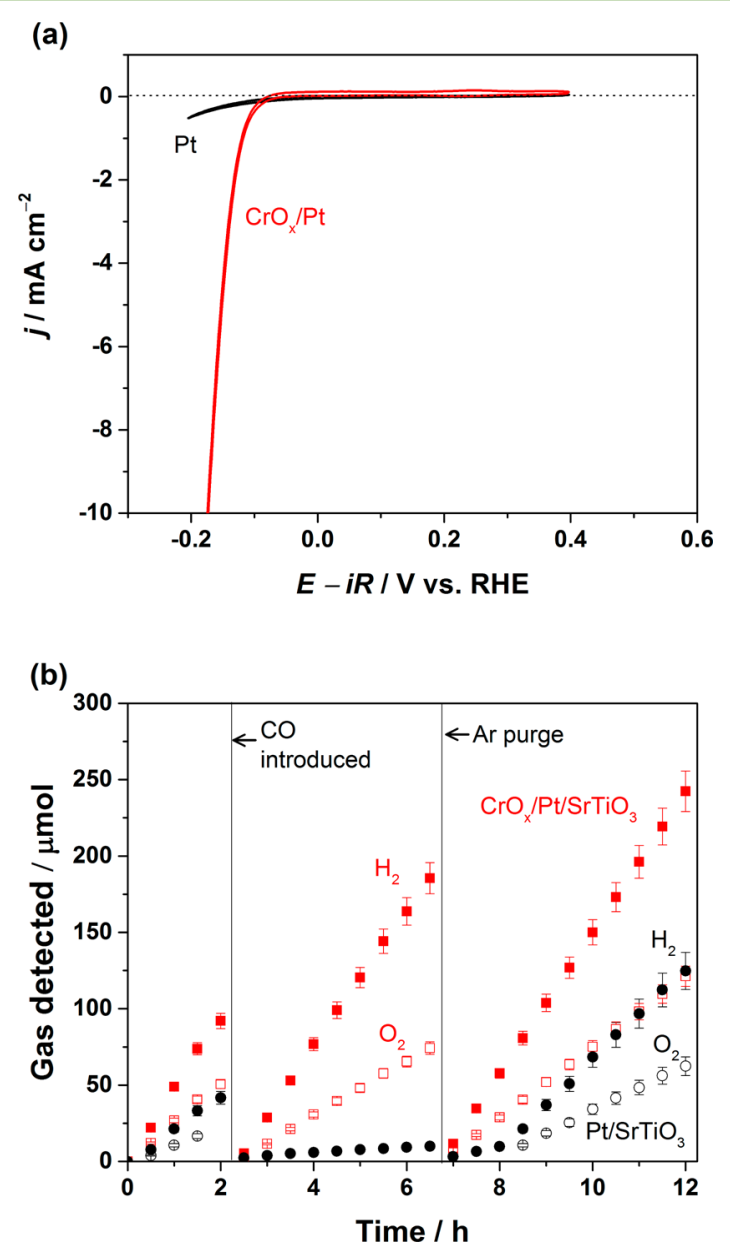

Figure 7. (a) Cyclic voltammograms over pristine $\mathrm{Pt}$ and $\mathrm{Cr}$-modified $\mathrm{Pt}\left(\mathrm{CrO}_{x} / \mathrm{Pt}\right)$ disk electrodes recorded at a scan rate of $50 \mathrm{mV} \mathrm{s}^{-1}$, a disk rotation speed of $3600 \mathrm{rpm}$, and $298 \mathrm{~K}$ in $0.1 \mathrm{M} \mathrm{NaOH}$ with $1 \%$ $\mathrm{CO} / \mathrm{Ar}$ bubbling. (b) Photocatalytic activity time courses of $\mathrm{Pt} /$ $\mathrm{SrTiO}_{3}$ and $\mathrm{CrO}_{x} / \mathrm{Pt} / \mathrm{SrTiO}_{3}$ in Milli-Q water with $1 \% \mathrm{CO}$ bubbling (100 $\mathrm{mL}$ of solution, under UV light irradiation $(300<\lambda<800 \mathrm{~nm})$ with $50 \mathrm{mg}$ of catalyst). 
potentials less than $-0.2 \mathrm{~V}$ vs RHE. The observed HER rate was substantially smaller than those in all other cases and can be accounted for by the $\mathrm{CO}$ molecules sticking to the $\mathrm{Pt}$ surface. However, when the $\mathrm{CrO}_{x}$ shell was present, substantially increasing reduction current was observed when the potential was $<0 \mathrm{~V}$ vs $\mathrm{RHE}$; this current was ascribed to HER and was quantitatively almost the same as the HER activity in the absence of $\mathrm{CO}$ (see Figure S12). This observation clearly shows that the $\mathrm{CrO}_{x}$ shell is capable of preventing $\mathrm{Pt}$ poisoning from $\mathrm{CO}$ without losing the HER activity of the Pt substrate.

Figure $7 \mathrm{~b}$ shows photocatalytic time courses of $\mathrm{Pt} / \mathrm{SrTiO}_{3}$ and $\mathrm{CrO}_{x} / \mathrm{Pt} / \mathrm{SrTiO}_{3}$ in Milli-Q water with $\mathrm{Ar}$ or $40 \mathrm{kPa}$ of $1 \%$ $\mathrm{CO} /$ Ar. During the first $2 \mathrm{~h}$ of the experiment, the $\mathrm{H}_{2}$ evolution rates in water solution without $\mathrm{CO}$ in the system were 20 and $50 \mu \mathrm{mol} \mathrm{h}{ }^{-1}$ for $\mathrm{Pt} / \mathrm{SrTiO}_{3}$ and $\mathrm{CrO}_{x} / \mathrm{Pt} / \mathrm{SrTiO}_{3}$, respectively. When $\mathrm{CO}$ gas was introduced to the system at $2 \mathrm{~h}$, the $\mathrm{H}_{2}$ evolution rate of $\mathrm{Pt} / \mathrm{SrTiO}_{3}$ dropped to $2 \mu \mathrm{mol} \mathrm{h}{ }^{-1}$, most likely due to poisoning of $\mathrm{Pt}$ by $\mathrm{CO}$, consistent with the electrochemical study (Figure 7a). After 7 h, CO was purged from the system and replaced with $\mathrm{Ar}$; after a $1 \mathrm{~h}$ induction period, $\mathrm{Pt} / \mathrm{SrTiO}_{3}$ exhibited almost the same $\mathrm{H}_{2}$ evolution rate as in the beginning, indicating that the $\mathrm{CO}$ had desorbed from the $\mathrm{Pt}$ surface. In contrast, $\mathrm{CrO}_{x} / \mathrm{Pt} / \mathrm{SrTiO}_{3}$ exhibited an almost unchanged $\mathrm{H}_{2}$ evolution rate. Therefore, it is inferred that $\mathrm{CO}$ cannot poison the $\mathrm{Pt}$ when the $\mathrm{CrO}_{x}$ shell is present.

Reaction Conditions Suitable for Chromium Layer. The previous sections have shown that, in both electrocatalytic and photocatalytic systems, the $\mathrm{CrO}_{x}$ layer can successfully block outer-sphere reactions as well as reduction of anions, molecular species, and gases. Such a universal function of $\mathrm{CrO}_{x}$ seems surprising; however, its use has some drawbacks. As described in the section on persulfate, $\mathrm{CrO}_{x}$ likely undergoes local redox reactions with species that are present in the solution; $\mathrm{Cr}^{3+}$ is oxidized in these reactions, leading to the loss of $\mathrm{CrO}_{x}$. Such local redox events are studied electrochemically in detail in this section, using $\mathrm{O}_{2}$ as a model oxidizing agent. CV was carried out using a $\mathrm{CrO}_{x} / \mathrm{Pt} \mathrm{RDE}$ for 1800 cycles in the potential range of $-0.1-0.7 \mathrm{~V}$ vs RHE at a scan rate of $50 \mathrm{mV}$ $\mathrm{s}^{-1}$ in $1.0 \mathrm{M} \mathrm{NaOH}$ with $\mathrm{O}_{2}$ bubbling (Figure S13a). No substantial change in the $\mathrm{CV}$ was obtained, which indicates the excellent stability of the $\mathrm{CrO}_{x}$ shell under working conditions. Two obvious conditions under which $\mathrm{CrO}_{x}$ is unstable were oxidizing conditions above $0.7 \mathrm{~V}$ vs $\mathrm{RHE}$, in which the $\mathrm{CrO}_{x}$ was oxidized (Figure S14), and acidic $\mathrm{pH}$ ( $\mathrm{pH} 2$ and lower, Figure S15), both of which are consistent with the literature. ${ }^{23}$ In addition, the presence of $\mathrm{O}_{2}$ was found to oxidize the $\mathrm{CrO}_{x}$ shell in nonworking conditions. Figure $8 \mathrm{a}$ shows $\mathrm{CVs}$ of a $\mathrm{CrO}_{x} / \mathrm{Pt} \mathrm{RDE}$ in $1.0 \mathrm{M} \mathrm{NaOH}$ with $\mathrm{O}_{2}$ bubbling in between successive scans while the rest time was sequentially increased. The CV after $1 \mathrm{~min}$ of resting conditions exhibited almost negligible current from 0 to $0.7 \mathrm{~V}$ vs RHE and increasing reduction current when the potential was $<0 \mathrm{~V}$ vs RHE, which is ascribable to HER; this is consistent with all the other CVs of $\mathrm{CrO}_{x} / \mathrm{Pt}$ in this study. While increasing the duration of the resting time to $30 \mathrm{~min}$ and $1 \mathrm{~h}$ did not lead to any significant changes in the $\mathrm{CV}$, the $\mathrm{CV}$ after $2 \mathrm{~h}$ of resting conditions with $\mathrm{O}_{2}$ bubbling exhibited reduction current from 0 to $0.7 \mathrm{~V}$ vs RHE. The open-circuit potential (OCP) that was recorded during the resting conditions is presented in Figure S13b and reveals that the OCP shifted to positive values, reaching $1.1 \mathrm{~V}$ vs RHE. Such a positive potential was sufficient to oxidize and dissolve the $\mathrm{CrO}_{x}$ shell. ORR was observed as the reduction
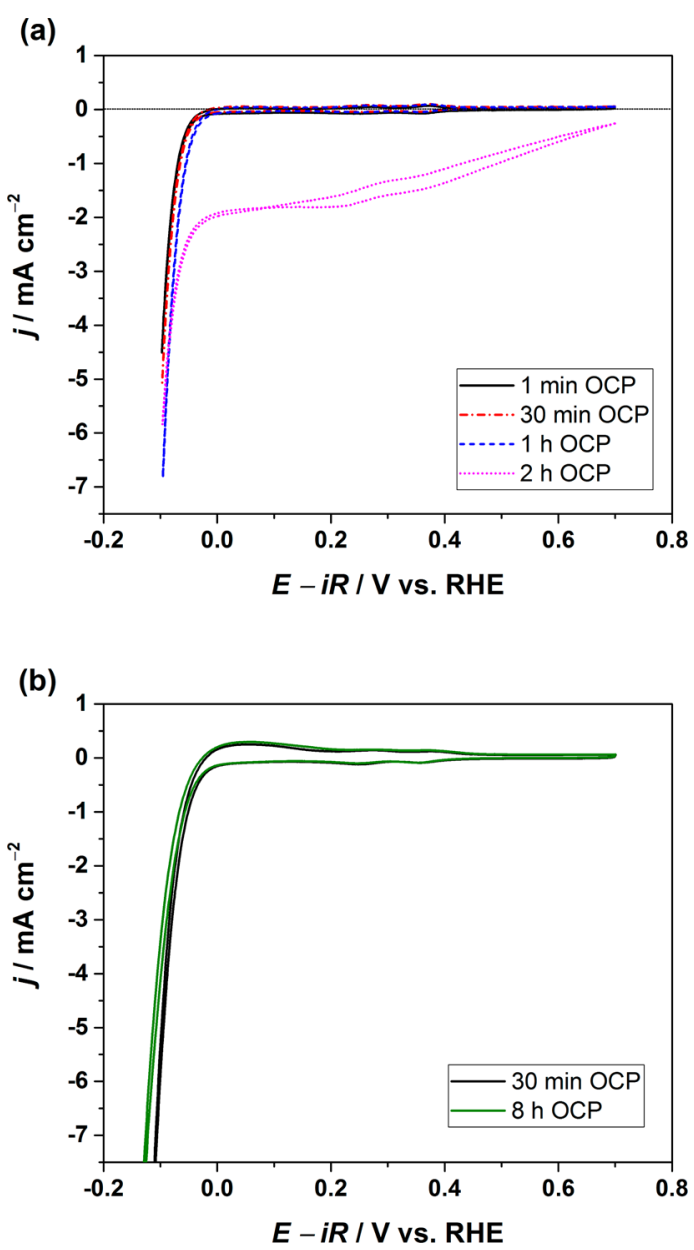

Figure 8. (a) Cyclic voltammograms over $\mathrm{Cr}$-modified $\mathrm{Pt}\left(\mathrm{CrO}_{x} / \mathrm{Pt}\right)$ disk electrodes in $1.0 \mathrm{M} \mathrm{NaOH}$ with sequentially increasing rest times between successive $\mathrm{CV}$ scans with (a) $\mathrm{O}_{2}$ bubbling and (b) $\mathrm{Ar}$ bubbling (disk rotation speed of $3600 \mathrm{rpm}$, scan rate of $50 \mathrm{mV} \mathrm{s}^{-1}$, and $298 \mathrm{~K})$.

current from 0 to $0.7 \mathrm{~V}$ vs RHE in Figure $8 \mathrm{a}$ and was most likely due to the loss of the $\mathrm{CrO}_{x}$ shell on the Pt surface. The same experiment was performed with Ar bubbling instead of $\mathrm{O}_{2}$, and the results are compiled in Figure 8b. Similar CVs were observed after different resting times, indicating that the $\mathrm{CrO}_{x}$ layer remained stable in the absence of $\mathrm{O}_{2}$. The stability of $\mathrm{CrO}_{x} / \mathrm{Pt} \mathrm{RDE}$ with $\mathrm{O}_{2}$ was further tested by a $10 \mathrm{~h}$ chronoamperometry (CA) study (see Figure S16a,b), where the potential was changed every hour to increasingly more cathodic current. Figure S16a showed that HER was stable at each potential and with both $\mathrm{Ar}$ and $\mathrm{O}_{2}$ gas. These results clearly showed that $\mathrm{CrO}_{x}$ is stable under working conditions, but $\mathrm{O}_{2}$ and $\mathrm{CrO}_{x}$ undergo local redox reactions when no current/potential is applied, resulting in the loss of the $\mathrm{CrO}_{x}$ shell from the catalyst surface.

The primary requirement for such losses of $\mathrm{CrO}_{x}$ is that the local redox reaction is thermodynamically allowed. The local redox reaction can thermodynamically occur when the equilibrium potential for the reduction of the oxidizing agent is at a more positive potential than the oxidation of $\mathrm{Cr}^{3+}$, or in other words, the local redox reaction is exothermic. Figure 9 compiles a Pourbaix diagram ${ }^{40}$ of representative half-reactions from this study. In the figure, cathodic half-reactions that are located at more positive potentials than the oxidation of $\mathrm{Cr}^{3+}$ 


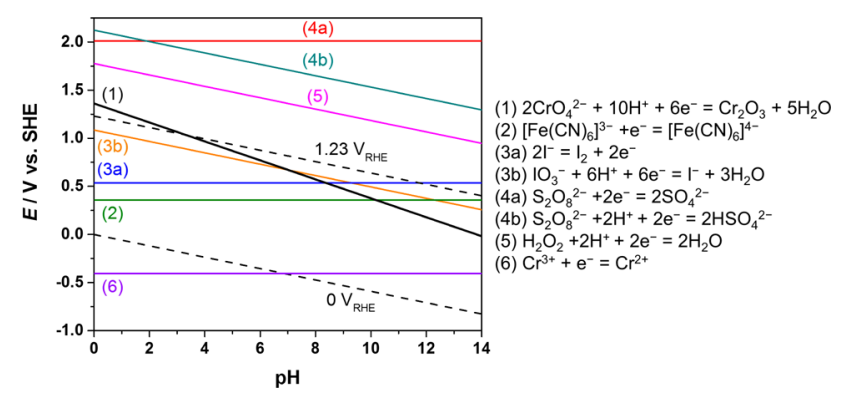

Figure 9. Pourbaix diagrams and corresponding reactions.

can undergo local redox events with $\mathrm{Cr}^{3+}$, i.e., the loss of the $\mathrm{CrO}_{x}$ shell. Among the species tested in this study, the loss of the $\mathrm{Cr}$ layer thermodynamically prevails in the presence of persulfate (at all $\mathrm{pH}$ levels), hydrogen peroxide (at all $\mathrm{pH}$ levels), oxygen (at all $\mathrm{pH}$ levels), and $\mathrm{Fe}^{3+}(>\mathrm{pH} 10)$. Indeed, as observed in this study, the presence of $\mathrm{O}_{2}$ in $1.0 \mathrm{M} \mathrm{NaOH}$ or persulfate in $0.1 \mathrm{M} \mathrm{NaOH}$ resulted in local redox events; however, the presence of hydrogen peroxide did not cause local redox reactions, most likely due to its sluggish kinetics on $\mathrm{CrO}_{x}$ surfaces. Thus, for the practical application of the $\mathrm{CrO}_{x}$ layer, consideration of both thermodynamics and kinetics are of great significance; for example, under practical solar fuel production conditions via photocatalytic overall water splitting, the evolved oxygen can accumulate in the system and light does not irradiate all the time. Thus, the $\mathrm{CrO}_{x}$ shell can be lost. Therefore, to realize more practical solar fuel production systems, additional measures need to be taken.

\section{CONCLUSION}

The universal functionality of Cr-based layers decorating hydrogen evolution catalysts was explored in both electrocatalytic and photocatalytic systems. Our systematic study disclosed that selective HER was universally possible when decorating $\mathrm{Pt}$ electrode with a layer of $\mathrm{CrO}_{x}$, even in the presence of $\left[\mathrm{Fe}\left(\mathrm{CN}_{6}\right)\right]^{3-}, \mathrm{NaIO}_{3}, \mathrm{Na}_{2} \mathrm{~S}_{2} \mathrm{O}_{8}$, and $\mathrm{H}_{2} \mathrm{O}_{2}$. Additionally, the poisoning of $\mathrm{Pt}$ surfaces by $\mathrm{CO}$ gas was prevented by the $\mathrm{CrO}_{x}$ shell by regulating the access of $\mathrm{CO}$ to the Pt surface. As a result, efficient photocatalytic overall water splitting using the Cr-decorated electrocatalyst was efficiently achieved, even in the presence of such redox species. Nevertheless, it was also found that, in the presence of strong oxidizing agents, whose reduction potentials are located at more positive values than that of the oxidation of $\mathrm{Cr}^{3+}$, local redox events can occur under dark condition, leading to the loss of $\mathrm{Cr}$. The presence of persulfate and $\mathrm{O}_{2}$ resulted in the gradual loss of the $\mathrm{CrO}_{x}$ shell due to such local redox events in nonoperating (open-circuit) conditions. Therefore, although $\mathrm{CrO}_{x}$ layers stably function under HER operating conditions (at negative potential), an additional strategy to mitigate the local redox reactions seems essential for the practical application of photocatalytic systems.

\section{ASSOCIATED CONTENT}

\section{S Supporting Information}

The Supporting Information is available free of charge on the ACS Publications website at DOI: 10.1021/acssuschemeng.7b01704.

CVs, photocatalytic time courses, control experiments, and additional characterization (PDF)

\section{AUTHOR INFORMATION}

\section{Corresponding Author}

*E-mail: kazuhiro.takanabe@kaust.edu.sa. Phone: +966 12808 4485.

ORCID $\odot$

Kazuhiro Takanabe: 0000-0001-5374-9451

\section{Present Address}

${ }^{\dagger}$ Department of Chemistry and Applied Biosciences, Institute for Chemical and Bioengineering, ETH Zurich, Vladmir-PrelogWeg 1, CH-8093 Zurich, Switzerland.

\section{Notes}

The authors declare no competing financial interest.

\section{ACKNOWLEDGMENTS}

The authors thank Dr. Dalaver H. Anjum for the TEM images. The research reported in this work was supported by the King Abdullah University of Science and Technology.

\section{REFERENCES}

(1) Takanabe, K.; Domen, K. Toward Visible Light Response: Overall Water Splitting Using Heterogeneous Photocatalysts. Green 2011, 1, 313-322.

(2) Pinaud, B. A.; Benck, J. D.; Seitz, L. C.; Forman, A. J.; Chen, Z.; Deutsch, T. G.; James, B. D.; Baum, K. N.; Baum, G. N.; Ardo, S.; Wang, H.; Miller, E.; Jaramillo, T. F. Technical and economic feasibility of centralized facilities for solar hydrogen production via photocatalysis and photoelectrochemistry. Energy Environ. Sci. 2013, 6, 1983-2002.

(3) Kudo, A.; Miseki, Y. Heterogeneous photocatalyst materials for water splitting. Chem. Soc. Rev. 2009, 38, 253-278.

(4) Nurlaela, E.; Wang, H.; Shinagawa, T.; Flanagan, S.; Ould-Chikh, S.; Qureshi, M.; Mics, Z.; Sautet, P.; Le Bahers, T.; Cánovas, E.; Bonn, M.; Takanabe, K. Enhanced Kinetics of Hole Transfer and Electrocatalysis during Photocatalytic Oxygen Evolution by Cocatalyst Tuning. ACS Catal. 2016, 6, 4117-4126.

(5) Qureshi, M.; Takanabe, K. Insights on Measuring and Reporting Heterogeneous Photocatalysis: Efficiency Definitions and Setup Examples. Chem. Mater. 2017, 29, 158-167.

(6) Ran, J.; Zhang, J.; Yu, J.; Jaroniec, M.; Qiao, S. Z. Earth-abundant cocatalysts for semiconductor based photocatalytic water splitting. Chem. Soc. Rev. 2014, 43, 7787-7812.

(7) Walter, M. G.; Warren, E. L.; McKone, J. R.; Boettcher, S. W.; Mi, Q.; Santori, E. A.; Lewis, N. S. Solar Water Splitting Cells. Chem. Rev. 2010, 110, 6446-6473.

(8) Dionigi, F.; Vesborg, P. C. K.; Pedersen, T.; Hansen, O.; Dahl, S.; Xiong, A.; Maeda, K.; Domen, K.; Chorkendorff, I. Suppression of the water splitting back reaction on $\mathrm{GaN}: \mathrm{ZnO}$ photocatalysts loaded with core/shell cocatalysts, investigated using a $\mu$-reactor. J. Catal. 2012, 292, 26-31.

(9) Wang, Q.; Hisatomi, T.; Jia, Q.; Tokudome, H.; Zhong, M.; Wang, C.; Pan, Z.; Takata, T.; Nakabayashi, M.; Shibata, N.; Li, Y.; Sharp, I. D.; Kudo, A.; Yamada, T.; Domen, K. Scalable water splitting on particulate photocatalyst sheets with a solar-to-hydrogen energy conversion efficiency exceeding 1\%. Nat. Mater. 2016, 15, 611-615.

(10) Takanabe, K. Solar Water Splitting Using Semiconductor Photocatalyst Powders. Top. Curr. Chem. 2015, 371, 73-103.

(11) Maeda, K.; Teramura, K.; Lu, D.; Saito, N.; Inoue, Y.; Domen, K. Noble-Metal $/ \mathrm{Cr}_{2} \mathrm{O}_{3}$ Core/Shell Nanoparticles as a Cocatalyst for Photocatalytic Overall Water Splitting. Angew. Chem., Int. Ed. 2006, 45, 7806-7809.

(12) Maeda, K.; Takata, T.; Hara, M.; Saito, N.; Inoue, Y.; Kobayashi, H.; Domen, K. GaN:ZnO Solid Solution as a Photocatalyst for VisibleLight-Driven Overall Water Splitting. J. Am. Chem. Soc. 2005, 127, $8286-8287$.

(13) Maeda, K.; Teramura, K.; Lu, D.; Takata, T.; Saito, N.; Inoue, Y.; Domen, K. Photocatalyst releasing hydrogen from water: 
Enhancing catalytic performance holds promise for hydrogen production by water splitting in sunlight. Nature 2006, 440, 295.

(14) Hisatomi, T.; Maeda, K.; Takanabe, K.; Kubota, J.; Domen, K. Aspects of the Water Splitting Mechanism on $\left(\mathrm{Ga}_{1-\mathrm{x}} \mathrm{Zn}_{\mathrm{x}}\right)\left(\mathrm{N}_{1-\mathrm{x}} \mathrm{O}_{\mathrm{x}}\right)$ Photocatalyst Modified with $\mathrm{Rh}_{2-\mathrm{y}} \mathrm{Cr}_{\mathrm{y}} \mathrm{O}_{3}$ Cocatalyst. J. Phys. Chem. C 2009, 113, 21458-21466.

(15) Maeda, K.; Teramura, K.; Masuda, H.; Takata, T.; Saito, N.; Inoue, Y.; Domen, K. Efficient Overall Water Splitting under VisibleLight Irradiation on $\left(\mathrm{Ga}_{1-\mathrm{x}} \mathrm{Zn}_{\mathrm{x}}\right)\left(\mathrm{N}_{1-\mathrm{x}} \mathrm{O}_{\mathrm{x}}\right)$ Dispersed with $\mathrm{Rh}-\mathrm{Cr}$ MixedOxide Nanoparticles: Effect of Reaction Conditions on Photocatalytic Activity. J. Phys. Chem. B 2006, 110, 13107-13112.

(16) Ohno, T.; Bai, L.; Hisatomi, T.; Maeda, K.; Domen, K. Photocatalytic Water Splitting Using Modified GaN:ZnO Solid Solution under Visible Light: Long-Time Operation and Regeneration of Activity. J. Am. Chem. Soc. 2012, 134, 8254-8259.

(17) Maeda, K.; Lu, D.; Teramura, K.; Domen, K. Simultaneous photodeposition of rhodium-chromium nanoparticles on a semiconductor powder: structural characterization and application to photocatalytic overall water splitting. Energy Environ. Sci. 2010, 3, 471-478.

(18) Domen, K.; Kudo, A.; Onishi, T.; Kosugi, N.; Kuroda, H. Photocatalytic Decomposition of Water into $\mathrm{H}_{2}$ and $\mathrm{O}_{2}$, over $\mathrm{NiO}$ $\mathrm{SrTiO}_{3}$, Powder Structure of the Catalyst. J. Phys. Chem. 1986, 90, 292-295.

(19) Han, K.; Kreuger, T.; Mei, B.; Mul, G. Transient Behavior of $\mathrm{Ni} @ \mathrm{NiO}_{\mathrm{x}}$ Functionalized $\mathrm{SrTiO}_{3}$ in Overall Water Splitting. ACS Catal. 2017, 7, 1610-1614.

(20) Zhang, L.; Liu, Q.; Aoki, T.; Crozier, P. A. Structural Evolution during Photocorrosion of $\mathrm{Ni} / \mathrm{NiO}$ Core/Shell Cocatalyst on $\mathrm{TiO}_{2}$. J. Phys. Chem. C 2015, 119, 7207-7214.

(21) Takata, T.; Pan, C.; Nakabayashi, M.; Shibata, N.; Domen, K. Fabrication of a Core-Shell-Type Photocatalyst via Photodeposition of Group IV and V Transition Metal Oxyhydroxides: An Effective Surface Modification Method for Overall Water Splitting. J. Am. Chem. Soc. 2015, 137, 9627-9634.

(22) Garcia-Esparza, A. T.; Shinagawa, T.; Ould-Chikh, S.; Qureshi, M.; Peng, X.; Wei, N.; Anjum, D. H.; Clo, A.; Weng, T.-C.; Nordlund, D.; Sokaras, D.; Kubota, J.; Domen, K.; Takanabe, K. An OxygenInsensitive Hydrogen Evolution Catalyst Coated by a MolybdenumBased Layer for Overall Water Splitting. Angew. Chem. 2017, 129, 5874-5878.

(23) Yoshida, M.; Takanabe, K.; Maeda, K.; Ishikawa, A.; Kubota, J.; Sakata, Y.; Ikezawa, Y.; Domen, K. Role and Function of Noble-Metal/ Cr-Layer Core/Shell Structure Cocatalysts for Photocatalytic Overall Water Splitting Studied by Model Electrodes. J. Phys. Chem. C 2009, 113, 10151-10157.

(24) Shinagawa, T.; Cao, Z.; Cavallo, L.; Takanabe, K. Photophysics and electrochemistry relevant to photocatalytic water splitting involved at solid-electrolyte interfaces. J. Energy Chem. 2017, 26, 259-269.

(25) Takanabe, K. Transferring Knowledge of Electrocatalysis to Photocatalysis: Photocatalytic Water Splitting. In Nanotechnology in Catalysis: Applications in the Chemical Industry, Energy Development, and Environment Protection; Sels, B., Voorde, M. V., Eds.; Wiley-VCH: 2017.

(26) Sahel, K.; Elsellami, L.; Mirali, I.; Dappozze, F.; Bouhent, M.; Guillard, C. Hydrogen peroxide and photocatalysis. Appl. Catal., B 2016, 188, 106-112.

(27) Maeda, K. Z-Scheme Water Splitting Using Two Different Semiconductor Photocatalysts. ACS Catal. 2013, 3, 1486-1503.

(28) Li, H.; Tu, W.; Zhou, Y.; Zou, Z. Z-Scheme Photocatalytic Systems for Promoting Photocatalytic Performance: Recent Progress and Future Challenges. Adv. Sci. 2016, 3, 1500389.

(29) Schneider, J.; Bahnemann, D. W. Undesired Role of Sacrificial Reagents in Photocatalysis. J. Phys. Chem. Lett. 2013, 4, 3479-3483.

(30) Bartholomew, C. H. Mechanisms of catalyst deactivation. Appl. Catal., A 2001, 212, 17-60.

(31) Ham, Y.; Hisatomi, T.; Goto, Y.; Moriya, Y.; Sakata, Y.; Yamakata, A.; Kubota, J.; Domen, K. Flux-mediated doping of $\mathrm{SrTiO}_{3}$ photocatalysts for efficient overall water splitting. J. Mater. Chem. A 2016, 4, 3027-3033.

(32) Marković, N. M.; Schmidt, T. J.; Stamenković, V.; Ross, P. N. Oxygen Reduction Reaction on Pt and Pt Bimetallic Surfaces: A Selective Review. Fuel Cells 2001, 1, 105-116.

(33) Shinagawa, T.; Garcia-Esparza, A. T.; Takanabe, K. Mechanistic switching by hydronium ion activity for hydrogen evolution and oxidation over polycrystalline $\mathrm{Pt}$ disk and $\mathrm{Pt} / \mathrm{C}$ electrodes. ChemElectroChem 2014, 1, 1497-1507.

(34) Shinagawa, T.; Takanabe, K. Identification of intrinsic catalytic activity for electrochemical reduction of water molecules to generate hydrogen. Phys. Chem. Chem. Phys. 2015, 17, 15111-15114.

(35) Wagner, C. D., Riggs, W. M., Davis, L. E., Moulder, J. F., Muilenberg, G. E., Eds. Handbook of X-ray Photoelectron Spectroscopy; Perkin-Elmer Corporation: Minneapolis, MN, 1979.

(36) Strmcnik, D.; Uchimura, M.; Wang, C.; Subbaraman, R.; Danilovic, N.; van der Vliet, D.; Paulikas, A. P.; Stamenkovic, V. R.; Markovic, N. M. Improving the hydrogen oxidation reaction rate by promotion of hydroxyl adsorption. Nat. Chem. 2013, 5, 300-306.

(37) Bard, A. J.; Faulkner, L. R. Electrochemical Methods Fundamentals and Applications; Wiley: New York, 2001.

(38) Higashi, M.; Abe, R.; Ishikawa, A.; Takata, T.; Ohtani, B.; Domen, K. Z-scheme Overall Water Splitting on Modified-TaON Photocatalysts under Visible Light $(\lambda<500 \mathrm{~nm})$. Chem. Lett. 2008, 37, 138-139.

(39) Maeda, K.; Abe, R; Domen, K. Role and Function of Ruthenium Species as Promoters with TaON-Based Photocatalysts for Oxygen Evolution in Two-Step Water Splitting under Visible Light. J. Phys. Chem. C 2011, 115, 3057-3064.

(40) Beverskog, B.; Puigdomenech, I. Revised Pourbaix Diagrams for Chromium at $25-300{ }^{\circ} \mathrm{C}$. Corros. Sci. 1997, 39, 43. 